\title{
Contact freezing: a review of experimental studies
}

\author{
L. A. Ladino Moreno ${ }^{1, *}$, O. Stetzer ${ }^{1}$, and U. Lohmann ${ }^{1}$ \\ ${ }^{1}$ Institute for Atmospheric and Climate Science, ETH Zurich, Universitätstrasse 16, 8092, Zurich, Switzerland \\ *now at: the Department of Chemistry, University of Toronto, Toronto, Ontario, Canada \\ Correspondence to: L. A. Ladino Moreno (1ladino@chem.utoronto.ca)
}

Received: 8 March 2013 - Published in Atmos. Chem. Phys. Discuss.: 21 March 2013

Revised: 22 August 2013 - Accepted: 23 August 2013 - Published: 2 October 2013

\begin{abstract}
This manuscript compiles both theoretical and experimental information on contact freezing with the aim to better understand this potentially important but still not well quantified heterogeneous freezing mode. There is no complete theory that describes contact freezing and how the energy barrier has to be overcome to nucleate an ice crystal by contact freezing. Experiments on contact freezing conducted using the cold plate technique indicate that it can initiate ice formation at warmer temperatures than immersion freezing. Additionally, a qualitative difference in the freezing temperatures between contact and immersion freezing has been found using different instrumentation and different ice nuclei. There is a lack of data on collision rates in most of the reported data, which inhibits a quantitative calculation of the freezing efficiencies. Thus, new or modified instrumentation to study contact nucleation in the laboratory and in the field are needed to identify the conditions at which contact nucleation could occur in the atmosphere. Important questions concerning contact freezing and its potential role for ice cloud formation and climate are also summarized.
\end{abstract}

\section{Introduction}

Clouds play an important role in the global radiative budget (Trenberth et al., 2009) as they cover around $70 \%$ of the Earth's surface (Stubenrauch et al., 2010). Depending on cloud type, clouds can either cool and/or heat the Earth's surface. Clouds reflect shortwave (solar) radiation cooling the Earth, and they can absorb and re-emit longwave radiation emitted by the Earth's surface back towards the surface causing a warming. Aerosol particles can act as cloud condensation nuclei (CCN), and a much smaller fraction of atmospheric aerosol particles act as heterogeneous ice nuclei (IN) to initiate ice formation below $0{ }^{\circ} \mathrm{C}$. Thus, aerosol particles are important in cloud formation (e.g., lifetime, droplet size, cloud phase and cloud albedo) and therefore influence the hydrological cycle (Lohmann and Feichter, 2005). Most of the precipitation in mid-latitudes originates via the ice phase but reaches the surface as rain (melting of ice crystals) (Lau and Wu, 2003; Lohmann and Feichter, 2005; Lohmann and Diehl, 2006). IN are mostly solid aerosol particles, either insoluble or crystalline. IN are thought to have a similar crystalline structure to ice and/or the possibility to form hydrogen bonds and to possess active sites (i.e., crevasses, imperfections, corners and/or steps onto the particle surface). Possible physical and chemical influences are summarized in Pruppacher and Klett (1997) and Vali (1999) (e.g., water uptake, particle morphology, hygroscopicity and presence of ions between the particle layers). Natural aerosol particles such as bioaerosols (e.g., bacteria, pollen and fungi), volcanic ash and soil particles (e.g., mineral dust and clays) have been found to be good IN. Amorphous organic aerosols, such as citric acid, levoglucosan and raffinose (Murray et al., 2010; Wagner et al., 2012; Wilson et al., 2012), secondary organic aerosols (Wang et al., 2012; Ladino et al., 2013); and crystalline particles, such as ammonium sulfate (Abbatt et al., 2006) or hydrated sodium chloride (Wise et al., 2012) may also serve as IN. Artificial particles such as silver iodide (AgI) have been used in the laboratory and in cloud seeding studies (Wieringa and Holleman, 2006) because they were found to be efficient IN. Diehl and Mitra (1998), Gorbunov et al. (2001) and Möhler et al. (2005) found that soot particles can also act as IN, whereas other studies suggest that this is not always the case (DeMott et al., 1999; Dymarska et al., 2006; Friedman et al., 2011). Therefore, predicting the IN activity, if any, of atmospheric soot is limited by poor current understanding. 
To understand ice formation in mixed-phase clouds, it is crucial to study each of the four known heterogeneous ice nucleation modes (deposition nucleation, condensation freezing, immersion freezing and contact freezing) in detail. In addition, the influence of secondary ice formation should also be taken into account. The preference of one freezing mechanism over another depends on IN composition, temperature and supersaturation with respect to ice and/or water and the presence of liquid supercooled droplets. Deposition nucleation occurs when water vapor deposits onto an IN. In contrast, condensation freezing occurs when water vapor condenses around the particle at temperatures below $0{ }^{\circ} \mathrm{C}$ to form a supercooled liquid droplet which subsequently freezes. Immersion freezing takes place when an IN is immersed within a liquid droplet at temperatures where it does not freeze and subsequently the liquid droplet is cooled down and initiates ice formation. The last heterogeneous freezing mode is contact freezing. Rau (1950); Fletcher $(1969,1970)$; Cooper (1974) and Fukuta (1975a) presented some of the first ideas on the concept of contact freezing. Contact freezing is defined as the process in which freezing of a supercooled droplet results from the collision with an aerosol particle (Vali (1985) and definitions by the International Commission on Clouds and Precipitation (ICCP) and the International committee on Nucleation and Atmospheric Aerosols (ICNAA)). Ice formation can be enhanced by contact freezing within mixed-phase clouds since both aerosol particles and supercooled cloud droplets may be present. Inside these clouds, the interstitial aerosol particles collide with the supercooled liquid droplets by different physical forces such as Brownian motion, inertial impaction, interception, electroscavenging, thermophoresis and diffusiophoresis (Greenfield, 1957; Slinn and Hales, 1971; Beard, 1974; Wang et al., 1978).

In the past, a lot of work has been done to study the conditions relevant for the different heterogeneous modes of ice formation. Here we only discuss studies of contact and immersion freezing with which contact freezing will be compared. These two freezing modes are frequently compared; however, this comparison is not trivial and requires more attention. Several experiments on immersion freezing using different instrumentation (e.g., the cold plate technique (Koop et al., 1998; Shaw et al., 2005; Vali, 2008; Rigg et al., 2013), the Differential Scanning Calorimeter (DSC, Marcolli et al., 2007), the wind tunnel (Pitter and Pruppacher, 1973; Diehl et al., 2002; Von Blohn et al., 2005), the Immersion Mode Cooling Chamber (IMCA, Lüönd et al., 2010) and the Leipzig Aerosol Cloud Interaction Simulator (LACIS, Niedermeier et al., 2010)) and different aerosol particles have been reported.

Since 1973 several research groups have studied contact freezing using different instrumentation such as cloud chambers (e.g., the NCAR ice nucleation counter (Langer et al., 1978), the thermal diffusion chamber (Schaller and Fukuta, 1979), the isothermal cloud chamber (ICC, DeMott et al., 1983; DeMott, 1995) and the CoLlision Ice Nucleation CHamber (CLINCH, Ladino et al., 2011b)), a wind tunnel (Pitter and Pruppacher, 1973; Levin and Yankofsky, 1983; Diehl and Mitra, 1998; Diehl et al., 2002; Von Blohn et al., 2005), a cold plate (Fukuta, 1975a; Rosinski and Nagamoto, 1976; Durant and Shaw, 2005; Shaw et al., 2005) and an ElectroDynamic Balance (EDB, Svensson et al., 2009; Hoffmann et al., 2013a, b). The collisions of the aerosol particles with droplets have been simulated in different ways. For example, Shaw et al. (2005); Durant and Shaw (2005) and Fornea et al. (2009) performed their experiments using the cold plate technique where the aerosol particles were brought into contact with the drops mechanically. In contrast, in the wind tunnel (e.g., Pitter and Pruppacher, 1973; Levin and Yankofsky, 1983; Diehl and Mitra, 1998; Von Blohn et al., 2005), EDB (Svensson et al., 2009; Hoffmann et al., 2013a, b) and cloud chamber studies (e.g., Langer et al., 1978; DeMott et al., 1983; DeMott, 1995; Ladino et al., 2011b) the aerosol particles were naturally scavenged from the air by the liquid drops.

Several detailed reviews on ice nucleation have been published (e.g., Mossop, 1963; Vali, 1985; Pruppacher and Klett, 1997; Hoose and Möhler, 2012; Murray et al., 2012). The ice nuclei concentrations, freezing pathways, proposed mechanisms and hypotheses to explain the laboratory observations have been revised. However, there is no paper that compiles the available information on contact freezing, which is suggested to be the pathway by which ice forms at the warmest temperatures for a given IN type based on the available laboratory data (e.g., Hoose and Möhler, 2012). Although contact nucleation can be a result of scavenging processes, the reason of the high measured freezing onset temperatures is still unknown. While some field studies support the atmospheric relevance of contact freezing (e.g., Auer Jr., 1971; Hobbs and Atkinson, 1976; Hobbs and Rangno, 1985; Ansmann et al., 2005; Seifert et al., 2011), some field studies (e.g., Twohy et al., 2010) and modeling studies (e.g., Cui et al., 2006; Phillips et al., 2007) found the opposite. Contact freezing has been observed to take place at the cloud top and at cloud edges where dry ambient air is mixed with cloudy air due to entrainment. This causes droplet evaporation and hence an increase in the collision rates due to thermophoresis. For example, Hobbs and Rangno (1985) proposed that contact freezing was responsible for the glaciation of the investigated cumulus clouds and the enhancement of ice formation took place at the top of the cloud due to entrainment. With the help of an aerosol Raman Lidar, Ansmann et al. (2005) observed ice formation in an altocumulus during the downdraft induced by a gravity wave. The observed freezing events were attributed to contact freezing and they took place at the edge of the cloud and in the downdraft region, similar to Hobbs and Rangno (1985). Seifert et al. (2011) showed the effectiveness of ash particles to nucleate ice in natural clouds. They reported that contact freezing may be responsible for the freezing events that took place at warm 
temperatures (i.e., $\leq 264 \mathrm{~K}$ ) in low and mid-level cloud layers. In contrast, Twohy et al. (2010) found that the measured orographic clouds at the Rocky Mountains were probably formed by immersion or condensation freezing in the regions containing water. No evidence for contact freezing was reported. Although contact freezing is favorable in evaporating clouds it may not be important in the convective clouds as shown by the modelling studies conducted by Cui et al. (2006) and Phillips et al. (2007), where immersion freezing was found to be the dominant pathway.

The above discrepancies stem from our incomplete understanding of this specific nucleation mode. Some of the identified parameters important for contact freezing from the field studies are the cloud type, saturation conditions, droplet size and concentration, aerosol particle size and concentration, and the downdraft/updraft environment. The proper conditions under which contact freezing is favorable are ambiguous and complex. Since we know so little about the atmospheric relevance of contact nucleation, the ice nucleation community needs to spend more time and effort working on it.

In addition to the previously mentioned field studies, there are also few attempts to measure contact freezing nuclei concentrations in the atmosphere (Deshler and Vali, 1992; Meyers et al., 1992). Deshler and Vali (1992) found that the contact freezing IN concentration at Laramie (Wyoming) varied from $1.7 \mathrm{~L}^{-1}$ (at $258 \mathrm{~K}$ ) to $3.1 \mathrm{~L}^{-1}$ (at $255 \mathrm{~K}$ ). Ambient aerosol particles with sizes close to $10 \mathrm{~nm}$ were allowed to collide, by diffusion and phoretic forces, with supercooled liquid drops with a diameter of $2600 \mu \mathrm{m}$. The droplets were suspended on thermocouples in order to determine their freezing temperatures. These field measurements are unique so far, therefore more efforts in this direction are needed. Field measurements are necessary to infer the atmospheric relevance of the laboratory observations before implemented in climate models. An increase in the numbers of contact freezing nuclei by anthropogenic activities may impact the indirect effect of the aerosol particles, causing more precipitation and less reflection of solar radiation back to space (Lohmann, 2002).

Hoose et al. (2010) developed a parameterization to calculate the contact freezing nucleation rates with the aim to investigate the importance of this freezing mode in global climate models and hence on climate. The obtained rates for soot particles are comparable to that of soot in the immersion freezing mode. However, the rates for dust particles are lower than the corresponding values in the deposition nucleation and immersion freezing modes because of the large size of dust particles that renders collisions less likely than in the case of soot.

In this manuscript we summarize the available theories, instrumentation and laboratory studies on contact freezing with a special focus on the experimental laboratory results and instrumentation but we leave out the field experiments. We highlight uncertainties of previous laboratory studies and suggest possible modifications in future experiments in order to increase their usefulness for the scientific community. The limitations of the currently available instrumentation are provided with the aim to build new and better instruments to study contact freezing in the future.

\section{Theory behind contact freezing}

The difficulty with experimentally studying contact freezing as well as describing it theoretically stems from the fact that contact freezing is a combination of two steps: the first step is the requirement that a collision between a supercooled droplet and aerosol particles takes place and the second step is the initiation of ice formation. The challenge is to deconvolve these two steps and describe them independently.

\subsection{Collision efficiency}

Collision efficiency $(C E)$ describes the fraction of aerosol particles in the sweep-out volume that effectively comes into contact with a droplet, falling by its terminal velocity. Figure 1 shows a schematic of how aerosol particles can collide with sedimenting water droplets due to different forces. Note that these scavenging processes are not restricted to contact freezing since they also influence immersion freezing.

The aerosol particles within the sweep-out volume can be moved towards or away from the cloud droplets by the air molecules due to their random movements. This effect, termed Brownian motion, is most important for small aerosol particles (aerosol particles (a) smaller than $\approx 0.1 \mu \mathrm{m}$ in radius). The smaller the particles, the larger the Brownian motion effect. When the aerosol particle radii are larger than $\approx 0.5 \mu \mathrm{m}$, their inertia are large enough to deviate from the trajectories of the surrounding air and impact onto the cloud droplets. Interception occurs when particles are of sizes that enable them to follow the parcel trajectories around the droplet but end up in the droplet boundary layer, very close to its surface where they are "intercepted" by the droplet. Interception is important in the same particle size range as inertial impaction. If electrical charges are present both on the aerosol particles and droplets, the aerosol particles can be attracted by the charges on the droplet. The phoretic forces (thermophoresis and diffusiophoresis) take place when cloud droplets are evaporating or growing by condensation. During evaporation or growth by condensation a temperature gradient between the droplet and its surrounding is created. Air molecules at the warmer side have a higher kinetic energy and thus exert a net force on the particles towards the colder temperature (thermophoresis). At the same time, a water vapor gradient (diffusiophoresis) is generated in the opposite direction, which moves the aerosol particles in the opposite direction as thermophoresis. Electroscavenging and the phoretic forces are relatively more important in the "Greenfield gap", i.e., at the transition regime between 

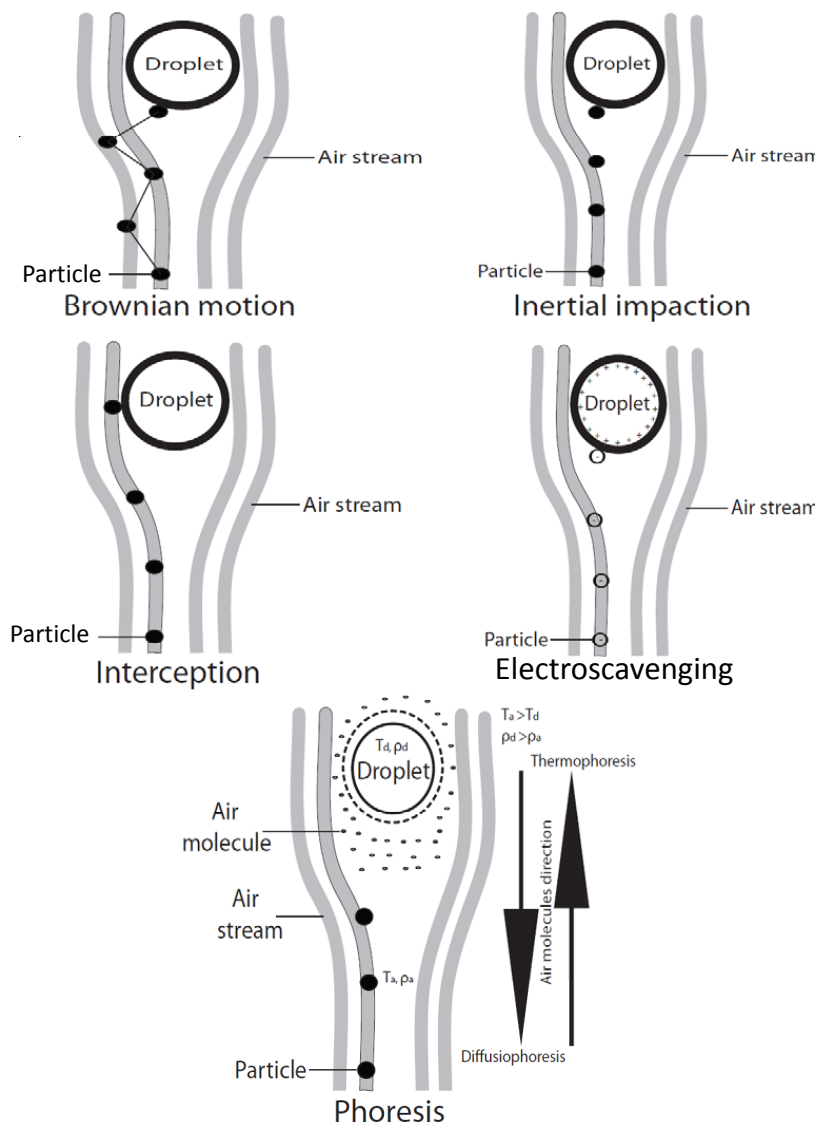

Fig. 1. Diagram of the different collision pathways between aerosol particles and cloud droplets relevant to contact freezing (Ladino, 2011).

Brownian motion and inertial impaction (aerosol particles from $\approx 0.1 \mu \mathrm{m}$ to $\approx 1.0 \mu \mathrm{m}$ in radius).

Several experimental (e.g. Beard, 1974; Lai et al., 1978; Leong et al., 1982; Deshler, 1985; Pranesha and Kamra, 1996; Vohl et al., 2001; Ladino et al., 2011a) and theoretical (e.g., Greenfield, 1957; Slinn and Hales, 1971; Isaac and Douglas, 1972; Wang et al., 1978; Herbert and Beheng, 1986; Tinsley et al., 2001; Park et al., 2005; Andronache et al., 2006; Croft et al., 2009) studies have been conducted to quantify the efficiency at which cloud drops and aerosol particles collide as a function of particle size and concentration, droplet size, relative humidity $\left(\mathrm{RH}_{\mathrm{W}}\right)$ and electric fields. Most of the parameterizations and/or models to determine the collision rates were developed for conditions below cloud with the exception of the Isaac and Douglas (1972), the Young (1974a) and the Wang et al. (1978) models.

Figure 2 shows the collision efficiency as a function of particle size and $\mathrm{RH}_{\mathrm{w}}$ using a combination of Wang et al. (1978), Park et al. (2005)'s and Andronache et al. (2006)'s models as an illustration. Although Wang et al. (1978) assumed the simultaneous action of the dynamical forces, with only the net force acting on the particle; Park et al. (2005) and Andronache et al. (2006) assumed different forces to act independently. Therefore, they added the single forces to determine the total CE.

\subsection{Freezing efficiency}

The freezing efficiency is the freezing probability per droplet-particle collision. It is a function of temperature, $\mathrm{RH}_{\mathrm{w}}$, particle size, droplet size and sums up the particle properties influencing the freezing process in that mode.

Knowing the collision efficiencies with the particle's terminal velocity $\left(v_{\mathrm{t}}\right)$ (or particle diffusivity) and the aerosol number concentration $\left(N_{\mathrm{a}}\right)$, the number of particles $\left(N_{\text {coll }}\right)$, which effectively collide with the droplet, can be calculated as follows:

$N_{\text {coll }}(t)=\int \pi \cdot(r(t)+a)^{2} \cdot C E \cdot v_{\mathrm{t}}(t) \cdot N_{\mathrm{a}} d t$.

For a given residence time $(t)$ of a droplet $(r)$ in an environment with a constant temperature and aerosol concentration, an experimental frozen fraction $(F F)$ can be measured. Equation (1) relates to one droplet. To derive a frozen fraction it is necessary to average over many observations of individual droplets.

$F F(t)=\frac{N_{\text {frozen }}}{N_{\text {total }}}$,

where $N_{\text {frozen }}$ is the number of frozen droplets and $N_{\text {total }}$ is the total number of studied droplets (liquid + ice). Hence, the freezing efficiency $F E$, can be defined as follows:

$F E=\frac{F F(t)}{N_{\text {coll(t) }}}=\frac{N_{\text {frozen }}}{N_{\text {total }}} \frac{1}{\int \pi \cdot(r(t)+a)^{2} \cdot C E \cdot v_{\mathrm{t}}(t) \cdot N_{\mathrm{a}} d t}$.

\subsection{Theories about contact freezing}

Pruppacher and Klett (1997) summarized the theories which were available in the 1970s. They focused on active sites (e.g., Fletcher, 1969) as the main difference between contact freezing and the other heterogeneous freezing modes. Later on, Tabazadeh et al. (2002), Djikaev et al. (2002), Sear (2007) and Djikaev and Ruckenstein (2008) explained the differences between different heterogeneous modes based on thermodynamical models. The most plausible theories/hypothesis are briefly summarized below.

\subsubsection{IN solubility}

Fletcher (1970) and Guenadiev (1970) suggested that the solubility of the IN could explain the difference between immersion and contact freezing. The classical nucleation theory (CNT) suggests that the ice germ forms on an active site of the IN. Therefore, if the active site characteristics are changed or partially modified it could have consequences for the IN abilities. They suggest that most IN begin as dry and insoluble particles. If a partial soluble IN is immersed in a 


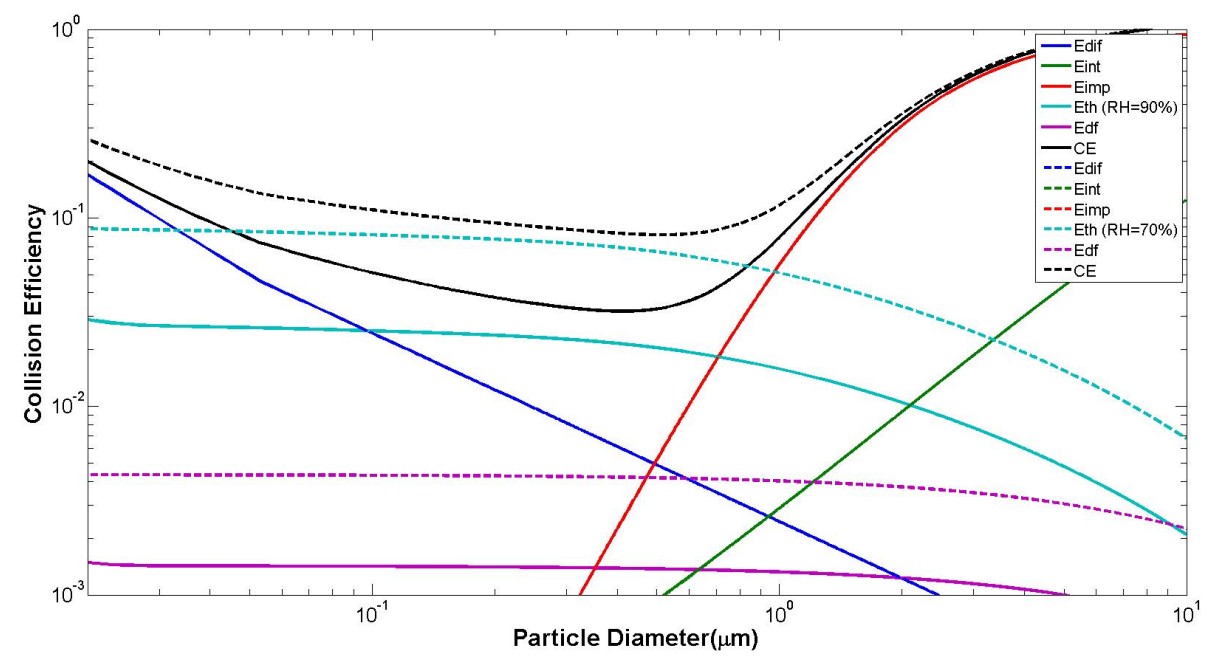

Fig. 2. Theoretical collision efficiency as a function of aerosol radius for a cloud droplet with a radius of $12.8 \mu \mathrm{m}$ and the contribution of each single force. $E_{\mathrm{dif}}, E_{\mathrm{int}}, E_{\mathrm{imp}}, E_{\mathrm{Th}}$ and $E_{\mathrm{Df}}$ are the collision efficiency due to Brownian motion, interception, inertial impaction, thermophoresis and diffusiophoresis respectively. $C E$ is the total collision efficiency. $E_{\mathrm{Th}}, E_{D f}$ and hence $C E$ have been calculated for a relative humidity $\left(\mathrm{RH}_{\mathrm{W}}\right)$ of $90 \%$ (solid lines) and for $\mathrm{RH}_{\mathrm{W}}=70 \%$ (dashed lines). The used air temperature was $297.0 \mathrm{~K}$, whereas the used droplet surface temperatures were $295.7 \mathrm{~K}$ and $292.8 \mathrm{~K}$ at a $\mathrm{RH}_{\mathrm{W}}$ of $90 \%$ and $70 \%$, respectively.

liquid droplet its surface can be eroded by the surrounding water molecules. As the active sites are located on the IN surface, they can be partially destroyed and/or their size reduced. This causes an IN deactivation or a decrease in the IN ability compared to an IN that collides with a cloud droplet from the outside and initiates freezing immediately. Note that particle erosion may also create new active sites on the particle surface (IN activation), the importance of which is unknown. This needs to be validated by laboratory studies.

\subsubsection{Ice embryo formation and its size}

Cooper (1974) was the first to explain contact freezing theoretically based on the CNT. He proposed a possible mechanism for this ice formation pathway. Figure 3 shows a schematic from Cooper (1974) where an ice germ forms on an IN due to deposition nucleation, immersion freezing and contact freezing. He proposed that a sub-critical (deposition nucleation) germ forms on the IN from the vapor phase. Upon contact with a supercooled droplet, freezing is triggered because the same ice embryo is supercritical when surrounded by water (immersion freezing). He assumes that the contact angle in both deposition nucleation and contact freezing is similar because the ice germ forms from the vapor phase. However, the critical ice embryo is larger for deposition nucleation than for contact nucleation which leads to a clear difference in the freezing (i.e., temperature) threshold between these modes. This is illustrated in Fig. 3 by the size of the shaded areas. Hoose et al. (2010) defined the ice embryo radius for deposition nucleation $\left(r_{\mathrm{g}, \mathrm{dep}}, \mathrm{Eq} .4\right)$ and immersion freezing $\left(r_{\mathrm{g}, \mathrm{imm}}\right.$, Eq. 5) based on Cooper (1974) and Chen et al. (2008). (a) Deposition

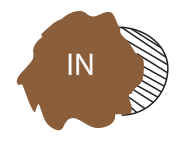

(b) Contact freezing
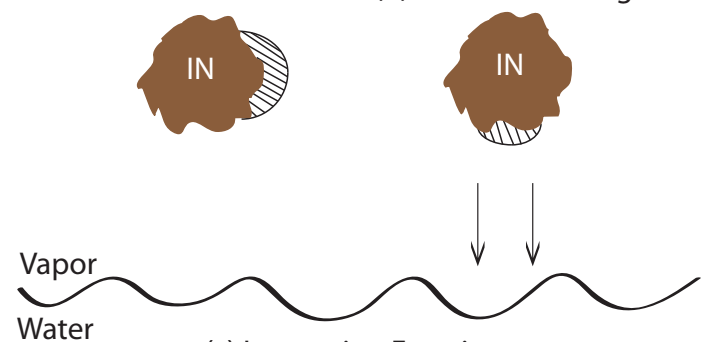

(c) Immersion Freezing
Fig. 3. Illustration of nucleation mechanisms, and the critical embryo sizes (shaded areas) required for nucleation (Cooper, 1974).

$\begin{aligned} r_{\mathrm{g}, \mathrm{dep}} & =\frac{2 v_{\mathrm{w}} \sigma_{\mathrm{i} / \mathrm{v}}}{k T \cdot \ln \left(e / e_{\mathrm{si}}\right)}, \\ r_{\mathrm{g}, \mathrm{imm}} & =\frac{2 v_{\mathrm{w}} \sigma_{\mathrm{i} / \mathrm{w}}}{k T \cdot \ln \left(a_{\mathrm{w}} e_{\mathrm{sw}} / e_{\mathrm{si}}\right)},\end{aligned}$

where $v_{\mathrm{w}}$ is the volume of a water molecule in ice, $\sigma_{\mathrm{i} / \mathrm{v}}$ the surface tension between ice and vapor, $\sigma_{\mathrm{i} / \mathrm{w}}$ surface tension between ice and water, $k$ the Boltzmann constant, $T$ the temperature, $e$ the water vapor pressure, $e_{\mathrm{si}}$ the saturation vapor pressure over ice, $a_{\mathrm{w}}$ the water activity, and $e_{\mathrm{sw}}$ the saturation vapor pressure over water.

The critical ice embryo size for contact freezing $\left(r_{\mathrm{g}, \mathrm{con}}\right)$ must be formed in the vapor phase and it should be equal to or larger than $r_{\mathrm{g}, \mathrm{imm}}$ in order to nucleate ice upon collision with 


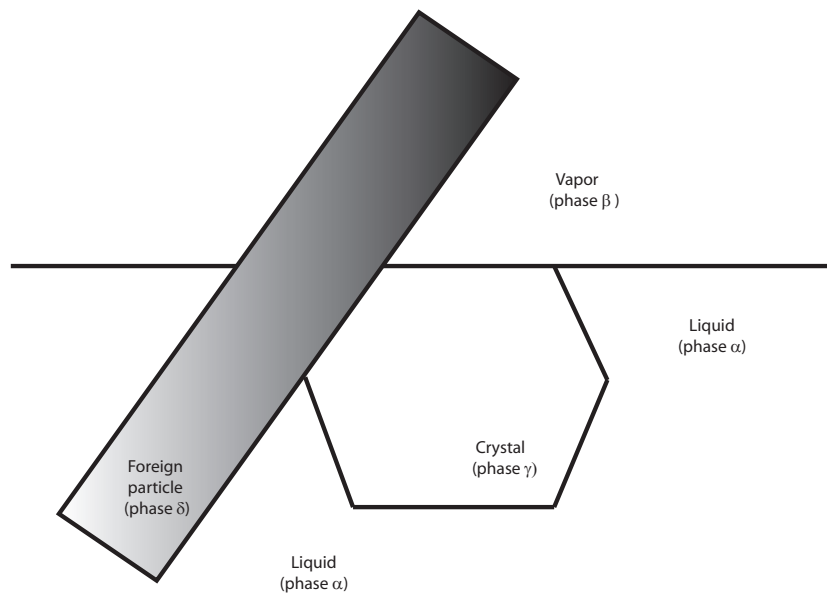

Fig. 4. Mechanism of contact freezing based on the different phases interactions (Djikaev and Ruckenstein, 2008).

a supercooled droplet. If $r_{\mathrm{g}, \text { con }}<r_{\mathrm{g}, \mathrm{imm}}$, the IN might diffuse into the droplet instead. However, it depends on the particle size and composition. Besides the critical ice embryo sizes, Cooper (1974) also developed a mathematical expression to calculate the number of contact ice germs per aerosol particle $\left(N_{\mathrm{g}, \text { contact }}\right)$. Cooper's idea is reflected in Equation 6 which is a modification from his original work (Hoose et al., 2010).

$N_{\mathrm{g}, \text { contact }}=4 \pi r_{N}^{2} \frac{e}{v_{s} \sqrt{2 \pi m_{w} k T}} \times \exp \left[-\frac{\Delta g_{\mathrm{dep}}^{\#}+f \Delta g_{\mathrm{g}, \text { hom }}^{\circ}\left(r_{\mathrm{g}, \mathrm{imm}}\right)}{k T}\right]$,

where $r_{\mathrm{N}}$ is the radius of the nucleus, $v_{\mathrm{s}}$ the frequency of vibration of water vapor molecules adsorbed on the solid substrate, $m_{\mathrm{w}}$ the mass of a water molecule, $\Delta \mathrm{g}_{\mathrm{dep}}^{\#}$ the activation energy for deposition nucleation, $f$ the form factor, and $\Delta \mathrm{g}_{\mathrm{g}, \mathrm{hom}}^{\circ}$ the homogeneous energy for germ formation in the vapor phase. Based on CNT, $f \Delta g_{\mathrm{g}, \mathrm{hom}}{ }^{\circ}$ is the energy of critical embryo formation for heterogeneous nucleation (Pruppacher and Klett, 1997; Chen et al., 2008). In this case $\Delta g_{\mathrm{g}, \text { hom }}^{\circ}$ is a function of $r_{\mathrm{g}, \text { imm }}$ since nucleation upon contact will only happen if $r_{\mathrm{g}, \mathrm{con}} \geq r_{\mathrm{g}, \mathrm{imm}}$ as mentioned above.

Cooper (1974)'s mechanism does not strictly require saturation with respect to water. He demonstrated that if the $\mathrm{RH}_{\mathrm{w}}$ is at or above $80 \%$, the IN should have a population of embryos on its surface to nucleate ice upon collision with a supercooled droplet.

The threshold difference was validated experimentally (e.g., Pitter and Pruppacher, 1973; DeMott, 1995; Diehl et al., 2001); however, discrepancies using AgI (similar nucleation thresholds for deposition nucleation and contact freezing (Pruppacher and Klett (1997), page 339) could not support this theory. Moreover, the particle size and relative humidity dependence on contact nucleation proposed by Cooper (1974) was not supported by the experiments conducted between the 1950s and 1970s. However, recent studies (e.g., Svensson et al. (2009) and Hoffmann et al. (2013a)) found a dependence on both parameters (see Sect. 3.3).
Fukuta (1975b) questioned a few points of Cooper's mechanism. He said that Cooper's mechanism does not include the high superiority or efficiency of contact freezing compared to immersion freezing. Additionally, he felt that the change of the ice embryo shape upon collision was not considered properly and that the number of deposition ice embryos (formed in the vapor-IN inter-phase) is not necessary larger than the number of immersion freezing ice embryos (formed in the liquid-IN inter-phase). However, Cooper (1975) argued that his original ideas were correct based on the assumptions made regarding the proposed mechanism.

\subsubsection{Mechanical disturbances}

Fukuta (1975a) tried to explain the difference in freezing temperatures between immersion and contact freezing as a consequence of the water-air interface movement on the IN. Water molecules adsorb on the dry IN surface while approaching the supercooled drop forming a layer of a variable thickness. The formed water clusters do not reach the critical size to form an ice embryo if the IN is brought in contact with a supercooled droplet until a transient high free energy is formed. This transient energy appears once the air-nucleus surface gets locally immersed into the supercooled droplet as a result of the collision between the IN and the droplet. If the previously mentioned conditions are given, the total free energy barrier is lowered enabling ice nucleation. The free energy of the embryo formation $\left(\Delta \mathrm{G}^{*}\right)$ and hence the $J_{\text {contact }}$ can be determined using Eqs. (7) and (8), respectively.

$$
\begin{aligned}
& \Delta G^{*}=\Delta \mu \cdot V+A_{\mathrm{CS}}\left(\gamma_{\mathrm{CS}}-\gamma_{\mathrm{CL}}\right)+A_{\mathrm{SL}} \cdot \gamma_{\mathrm{SL}}, \\
& J_{\text {contact }}=K \cdot \exp \left[\frac{-\Delta G^{*}}{k T}\right],
\end{aligned}
$$

where $\Delta \mu$ in the free energy difference between ice and water, $V$ the volume of the ice germ, $A_{\mathrm{CS}}$ the area between the IN and ice embryo boundary, $\gamma_{\mathrm{CS}}$ surface-free energy between the IN and ice embryo interface, $\gamma_{C L}$ surface-free energy between the IN and liquid interface, $A_{\mathrm{SL}}$ the area between the liquid and the ice embryo boundary, $\gamma_{\mathrm{SL}}$ surfacefree energy between the liquid and the ice embryo interface, and $K$ the kinetic constant.

This mechanism would also work if an aerosol particle, which was initially on the inside of a supercooled droplet, diffuses to the surface. This would only be possible if a change in the environment occurs and if a transient high free energy is formed under this scenario. The structure of water interacting with the substrate (i.e. particle) would change as the particle emerged from the bulk (W. Cantrell, personal communication, 2013).

There are several similarities between Cooper's and Fukuta's mechanisms. Both mechanisms are framed in terms of water adsorbed to the surface of the potential contact IN. Additionally, both depend on $\mathrm{RH}_{\mathrm{w}}$ and aerosol particle size (W. Cantrell, personal communication, 2013). As discussed 
in Sect. 3 the newest laboratory results on contact freezing discuss the influence of $\mathrm{RH}_{\mathrm{w}}$ and IN size.

\subsubsection{Three-phase contact}

Sear (2007) used a two-dimensional three-state Potts model to compare the nucleation rates of contact freezing with those of immersion freezing. Sear (2007) found that the nucleation rate at the three phase contact line (i.e., contact freezing) is orders of magnitude higher compared with a particle that is fully immersed in liquid water. Although this is a very general model based on thermodynamics, the author suggests that it can be extrapolated to more complex systems.

Another thermodynamical model was developed by Djikaev and Ruckenstein (2008) to investigate the same phenomena. In this model four different phases are taken into account as shown in Fig. 4. The different phases are the liquid and vapor phase, the ice crystal and the foreign particle which are symbolized with $\alpha, \beta, \gamma$ and $\delta$, respectively. The needed reversible work to nucleate an ice crystal at the double interphase $\alpha-\delta$ (immersion freezing) was calculated and compared with the corresponding values at the triple inter-phase $\alpha-\beta-\delta$ (contact freezing). Djikaev and Ruckenstein (2008) found that the required reversible work is smaller if the ice germ forms at the triple inter-phase i.e., when the IN is located at the droplet surface. Therefore, the energy barrier for contact freezing is smaller than for immersion freezing.

However, the energy barrier alone does not make a nucleation rate, which complicates the comparison between contact and immersion freezing. Since the two approaches are geometrically different, one may happen on any point on a line and the other on any point on a surface. Therefore, if we were to formulate nucleation rates out of the two theoretical descriptions, we would get two formulas with different units: per unit length and per unit surface. Thus, to decide if in practice, contact freezing is preferred over immersion freezing is not straightforward. It may turn out, that contact freezing is slower even if it has the lower energy barrier.

Recently, Gurganus et al. (2011) and Gurganus et al. (2013) reported experimental results which contradict the previously mentioned mechanisms. Using an improved and modified version of a cold stage (Suzuki et al., 2007) to avoid the point-like contact (i.e., the contact between the drop and the IN) and to minimize the temperature variation on the water drop surface, the preferred location to nucleate an ice crystal was investigated on silicon wafers. Gurganus et al. (2011) tested 189 drops and found that there is no preference to form the ice germ at the 3-phase boundary (surfacedroplet-air) or 3-phase contact line over the 2-phase contact area. Gurganus et al. (2013) confirmed their previous observations with an improved version of their experimental setup (i.e. a side view of the tested droplets was possible with a second high-speed camera).

\section{Experimental results and discussion}

Contact freezing became an important topic in the 1960s in the context of weather modification. Different instruments were developed, which will be briefly described in the following subsections. Table 1 summarizes previous studies on contact freezing using different instrumentation, IN type, particle and droplet sizes, relative humidities, aerosol particle and droplet concentrations. The first experimental studies focused on the IN properties of different organic materials and AgI; however, nowadays the scientific community is primarily focusing on bioaerosols, mineral dust and volcanic ash particles. Note that most of the studies were conducted with rain drops instead of cloud droplets, not all of them used monodisperse aerosol particles and often the number of collisions is unknown. It is therefore difficult to make a direct comparison between the different studies due to the large variability in the experimental conditions. Below, the most relevant results from each instrument are shown and discussed.

\subsection{Cold plate technique}

The cold plate technique is the oldest reported instrument to study contact freezing (Gokhale and Goold Jr, 1968). The cold plate consists of a metallic surface that is coated with a thin layer of hydrophobic material (e.g., paraffin) to repel water. There are two different ways to perform a contact freezing experiment using this technique. In the most common way, the liquid droplet is placed on the plate and the IN is located at the side of the drop but in touch with it (static cold plate). Thereafter, temperature is decreased until ice formation is observed. It typically uses one drop. Another possibility is to place the drop on the cold plate and then direct an air stream with aerosol particles towards the drop while temperature is reduced until the droplet freezes (dynamic cold plate). In this case it is possible to use more than one drop at the same time. The freezing of the drop(s) can be monitored using a high speed camera or other techniques. The relative humidity and hence evaporation can also be controlled. Figure 5 shows the apparatus used by Shaw et al. (2005) and Durant and Shaw (2005) with its main components.

The use of a single drop in a static cold plate results in lower statistics compared to other techniques. However, this is not the case if a dynamic cold plate is used where the statistics are comparable or even better than other techniques due to the high sensitivity to the first freezing events. The use of single drops and single particles on a static cold plate avoids the collision efficiency calculations and allows more precise freezing efficiency calculations. The cold plate technique provides useful information regarding the physical processes such as evaporation freezing, volume vs. surface nucleation and particle penetration after the collision takes place. 


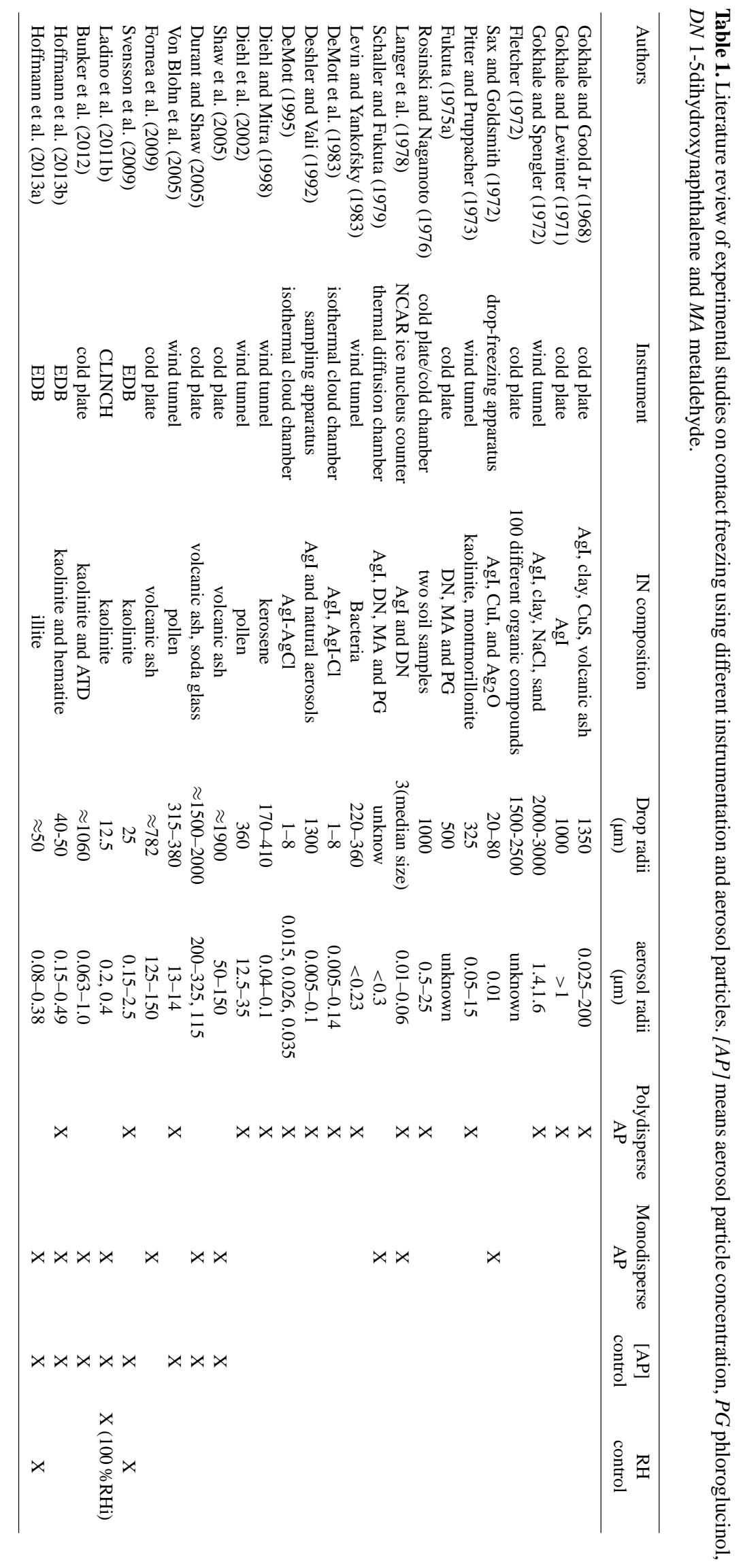


Table 2. Summary of the freezing temperatures for contact and immersion freezing conducted on a cold plate. $\widetilde{T}$ is the average onset freezing temperature (temperature at which the tested drops freeze) for contact freezing (CF), immersion freezing (IF) and homogeneous freezing (HF), respectively.

\begin{tabular}{|c|c|c|c|c|c|}
\hline Authors & Cold plate type & IN composition & $\widetilde{T}$ for $\mathrm{CF}(\mathrm{K})$ & $\widetilde{T}$ for IF $(\mathrm{K})$ & $\widetilde{T}$ for $\mathrm{HF}(\mathrm{K})$ \\
\hline Gokhale and Goold Jr (1968) & Dynamic & AgI,Clay, CuS, volcanic ash & 267 & {$[-]$} & 265 \\
\hline Gokhale and Lewinter (1971) & Dynamic & AgI & 267 & {$[-]$} & {$[-]$} \\
\hline Fukuta (1975a) & Dynamic & 1-5dihydroxynaphthalene & 266 & {$[-]$} & {$[-]$} \\
\hline Fukuta (1975a) & Dynamic & metaldehyde & 270 & {$[-]$} & {$[-]$} \\
\hline Fukuta (1975a) & Dynamic & phloroglucinol & 267 & {$[-]$} & {$[-]$} \\
\hline Rosinski and Nagamoto (1976) & Dynamic & two soil samples & 268 & {$[-]$} & {$[-]$} \\
\hline Shaw et al. (2005) & Static & volcanic ash & $254-255$ & 251 & $246-247$ \\
\hline Durant and Shaw (2005) & Static & glass-rich volcanic ash & 256 & 252 & {$[-]$} \\
\hline Durant and Shaw (2005) & Static & soda glass & 255 & 252 & {$[-]$} \\
\hline Fornea et al. (2009) & Static & Mount St. Helens Ash & 262 & 255 & {$[-]$} \\
\hline Fornea et al. (2009) & Static & IHSS Pahokee Peat Soil II & 263 & {$[-]$} & {$[-]$} \\
\hline Fornea et al. (2009) & Static & Carbon (Lampblack) & 248 & {$[-]$} & {$[-]$} \\
\hline Bunker et al. (2012) & Dynamic & kaolinite & 258 & {$[-]$} & {$[-]$} \\
\hline Bunker et al. (2012) & Dynamic & Arizona test dust & 256 & {$[-]$} & {$[-]$} \\
\hline
\end{tabular}
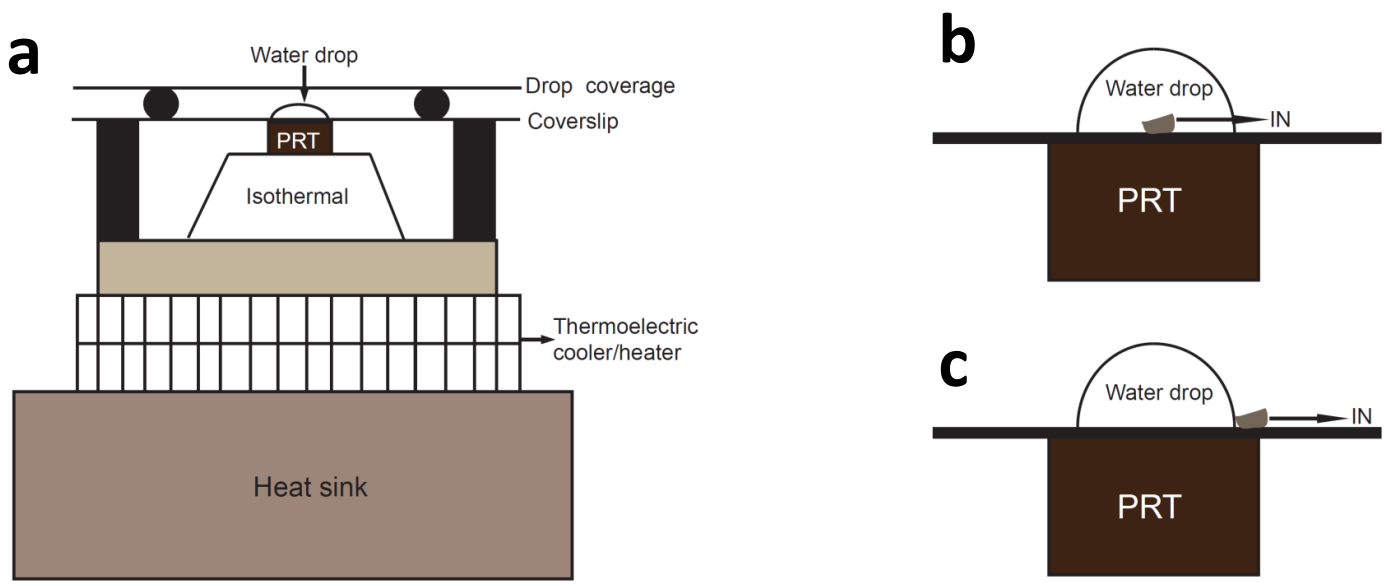

Fig. 5. (a) Schematic with the cold plate experimental setup (left), (b) of the IN for an immersion freezing (top right) and (c) for a contact freezing experiment (bottom right) (Shaw et al., 2005).

The first cold plate studies were conducted with polydisperse submicron aerosol particles, whereas the recent studies used large monodisperse aerosol particles such as volcanic ash. Table 2 summarizes the available studies conducted with the cold plate technique. The average onset freezing temperature (i.e., temperature at which the tested drop freezes) strongly depends on the chemical composition of the IN. Relatively pure AgI and metaldehyde were found to be very good materials to nucleate ice via contact freezing; however their atmospheric relevance is low.

In Gokhale and Goold Jr (1968) 20 drops were put on the cold plate at the same time and the aerosol particles were dropped on the drops without any mechanical help. The authors claimed that between 500 to 1000 particles reached each drop. A similar strategy was used by Bunker et al. (2012), however they only used one drop instead of 20 .
Bunker et al. (2012) found that kaolinite nucleates ice by contact freezing at $-18^{\circ} \mathrm{C}$, and ATD at $-15^{\circ} \mathrm{C}$. The very low calculated $F E\left(\approx 10^{-5}\right)$ suggests that at high temperatures, many collisions are required to nucleate ice.

Gokhale and Goold Jr (1968) and Gokhale and Lewinter (1971) showed that the AgI particles remain at the droplet surface after the collision, i.e., there is no particle penetration into the droplet. They also demonstrated that once a collision takes place, the freezing of the droplets needs 16-47 milliseconds to occur. Unfortunately, this behavior has not been further investigated with other instrumentation. The time dependence is important in order to evaluate the stochastic or deterministic behavior of contact freezing. This is crucial in order to apply relatively simple calculations of ice formation by contact freezing on the basis of determined freezing efficiencies (also termed ice nucleation activity). 


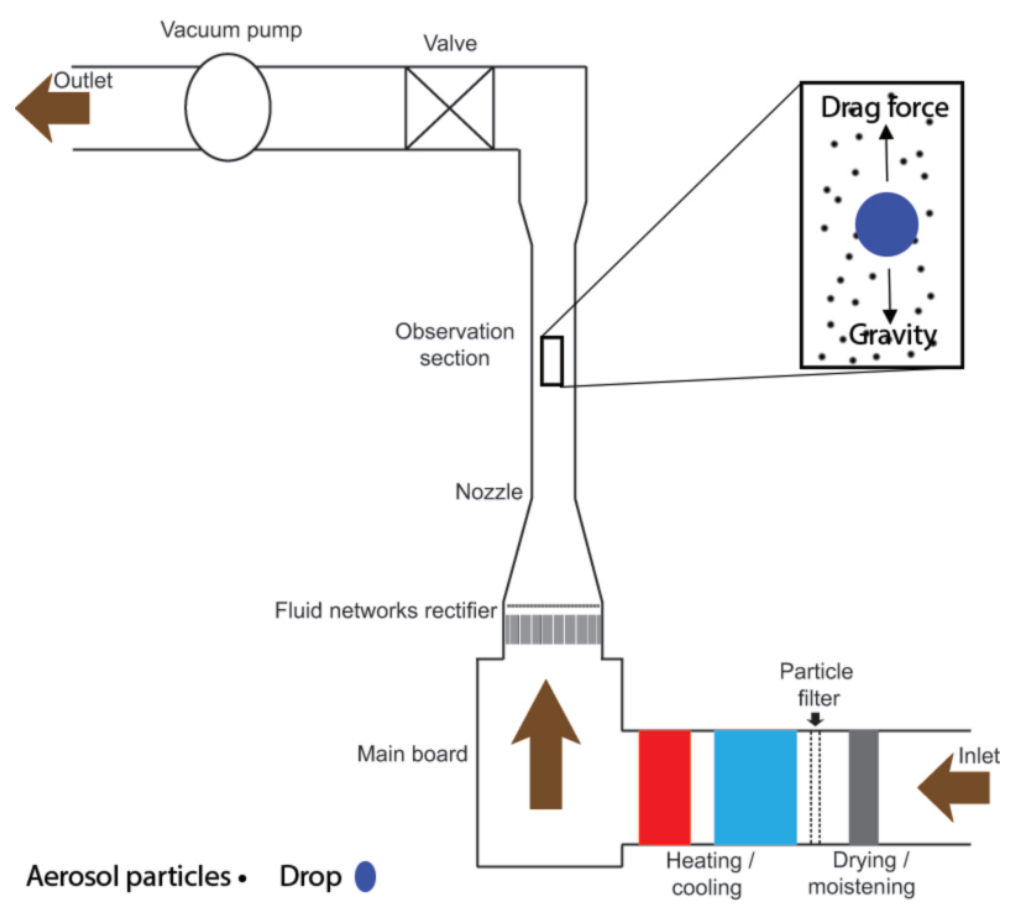

Fig. 6. Schematic of the wind tunnel experimental setup and its major components (Diehl et al., 2011; Szakáll et al., 2010).

The results from Shaw et al. (2005) and Durant and Shaw (2005) reveal very similar freezing temperatures for volcanic ash, glass-rich volcanic ash and soda glass particles. They provide evidence that it does not matter if the contact between the IN and the droplet surface is from the inside or the outside. Durant and Shaw (2005) speculate about evaporation and its importance in the atmosphere, given that evaporation causes immersed IN to come into contact with the droplet surface which could trigger freezing. Fornea et al. (2009) found that the Mount St. Helens ash particles are more efficient (by $7 \mathrm{~K}$ ) than the tested particles by Shaw et al. (2005) and Durant and Shaw (2005). These differences could be attributed to differences on the chemical composition of the investigated aerosol particles. All three studies also found an important difference of the onset freezing temperatures between contact and immersion freezing (see Sect. 3.6).

\subsection{Wind tunnel}

The first wind tunnel to study collision efficiencies was built in 1968 (Pruppacher and Neiburger, 1968; Beard and Pruppacher, 1969). Pruppacher developed an improved version of the wind tunnel at the University of Mainz that enabled contact freezing studies. In these studies a supercooled drop is suspended in a vertical air stream. The air mass is prehumidified to reduce evaporation. Particles are injected upstream and eventually hit the levitated supercooled drop. Freezing of the droplets after collisions is detected by a change in its appearance (i.e., opaque). Moreover, the flow balance also changes once the droplet freezes because its ter- minal velocity changes. Figure 6 shows a schematic of the wind tunnel with its relevant parts (Diehl et al., 2011; Szakáll et al., 2010).

Figure 7 shows contact freezing results from experiments conducted in a wind tunnel using five different particle types (bacteria, kaolinite, montmorillonite, soot and birch spores) as IN (Pitter and Pruppacher, 1973; Levin and Yankofsky, 1983; Diehl and Mitra, 1998; Diehl et al., 2002). They used almost the same droplet size (220-370 $\mu \mathrm{m}$ in diameter), however, because of the nature of the aerosol particles the IN sizes differed. Soot particles (radii) ranged from 0.05 to $0.1 \mu \mathrm{m}$, kaolinite and montmorillonite from 0.05 to $15 \mu \mathrm{m}$, birch spores are $>12.5 \mu \mathrm{m}$ and bacteria are $<0.23 \mu \mathrm{m}$ (the bacteria cells were passed through a grid of $0.45 \mu \mathrm{m}$ ). Assuming that the particle size influence is small, it is possible to compare these four different data sets as they used similar conditions and were conducted with the same instrument. The authors found that the five tested particles nucleated ice at temperatures higher than necessary for homogeneous freezing. Bacteria initiated ice formation at the highest temperatures $(269.7 \mathrm{~K})$. Interestingly, bacteria show a steep increase in the frozen fraction over a very narrow temperature range, which is not the case for the other tested materials. This steep increase is typically observed on homogeneous freezing experiments. The slopes of the frozen fractions with temperature strongly depend on the used IN.

A large uncertainty in the results presented in Fig. 7 is the aerosol particle concentration and hence the number of collisions between particles and droplets, since in some of those 


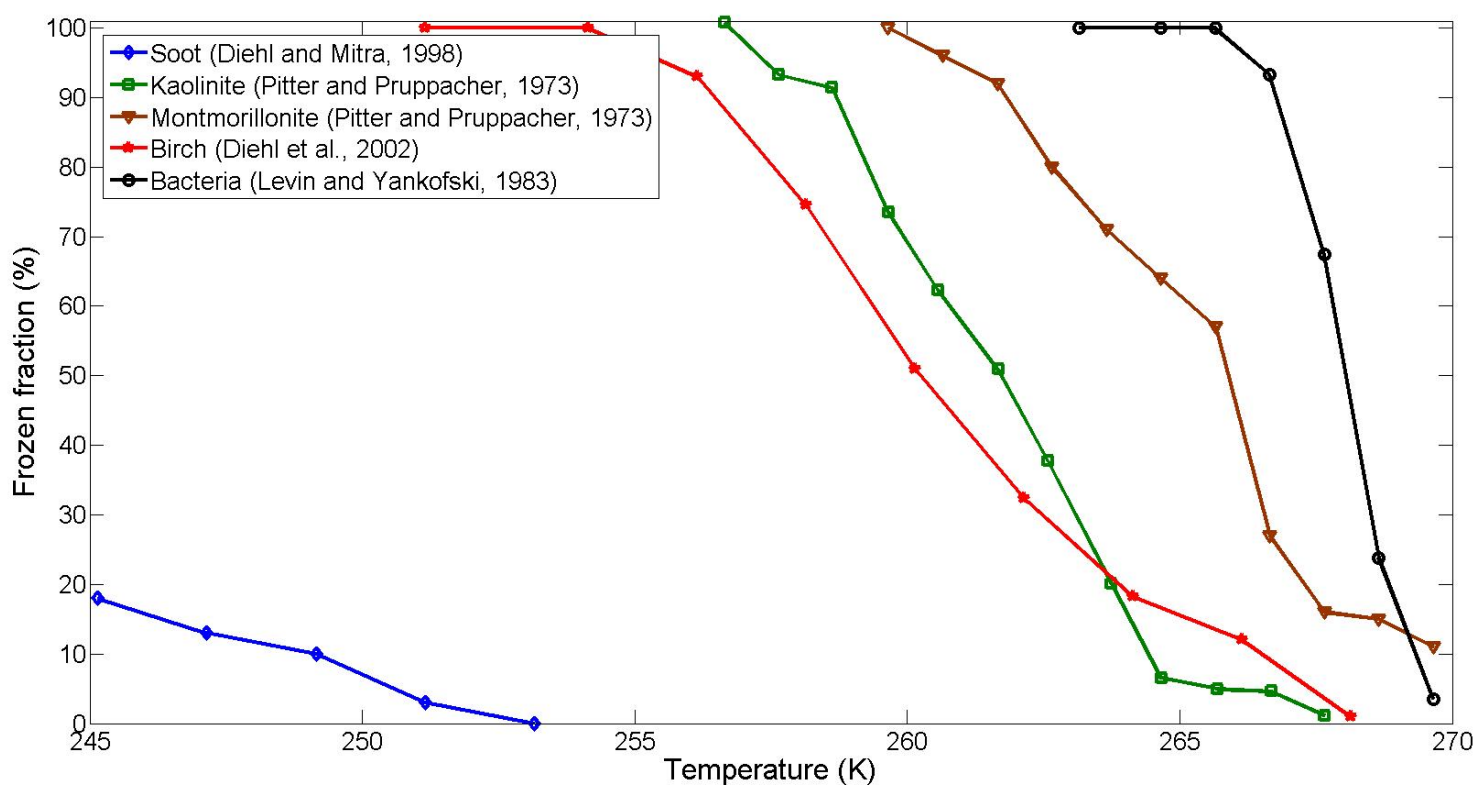

Fig. 7. Comparison of different contact freezing experiments conducted in a wind tunnel. Blue represents the experiments done with soot particles, green with kaolinite, brown with montmorillonite, red with pollen and black with bacteria (Pitter and Pruppacher, 1973; Levin and Yankofsky, 1983; Diehl and Mitra, 1998; Diehl et al., 2002).

studies it was neither measured nor controlled. This parameter is important in order to determine the collision rates and freezing efficiencies. Only frozen fractions can be reported. They strongly depend on experiment conditions and therefore do not represent the freezing probabilities of the tested particles. The study by Diehl and Mitra (1998) is the only exception where the aerosol concentration was between $10^{5}-$ $10^{6} \mathrm{~cm}^{-3}$, which is several orders of magnitude higher than IN concentrations found within a cloud (Deshler and Vali, 1992; Rogers, 1993; DeMott et al., 2003, 2010). If the collision rates for the used drops, particles and concentrations are given, the freezing efficiencies could be determined.

\subsection{Electrodynamic balance (EDB)}

The electrodynamic balance is a versatile instrument to study different physical properties and processes with single levitated liquid droplets (e.g., index of refraction, homogeneous ice nucleation, hygroscopicity and evaporation rates Davis and Ravindran, 1982; Stöckel et al., 2005; Soonsin et al., 2010). Recently the EDB has been used for contact freezing experiments as well (Svensson et al., 2009; Hoffmann et al., 2013a, b). The EDB consists of a double-ring electrode with two end cap electrodes. These concentric rings are supplied with AC and DC voltages. The DC field is used to keep the droplet in a balance (i.e., levitating between the rings) as this field acts against the effect of gravitation. Droplets of different sizes can be generated using an electrically charged syringe-needle system or with a piezoelectric droplet generator. Both systems ensure that the droplets are electrically charged, which is a requirement to control them by the electric fields in the EDB. Two CCD (charge coupled device) cameras are used to measure the droplet size via the intensity of light scattered by a laser beam. Fluctuations of the scattered light are used to detect the phase transition from liquid to solid (or solid to liquid) (Duft and Leisner, 2004a, b; Svensson et al., 2009). Figure 8 shows a schematic of the EDB with the alignment of the CCDs and the light source. Charged particles can be injected to collide with the levitating droplet (mainly due to electroscavenging). The air temperature, relative humidity and the total pressure within the EDB can be measured and adjusted.

Figure 9 shows the available contact freezing experiments conducted with an EDB (Svensson et al., 2009; Hoffmann et al., 2013a, b). All three studies reported the freezing probability or FE of different mineral dust particles to nucleate ice crystals. Svensson et al. (2009) found that the FE increases with decreasing temperature and increasing relative humidity. Although the collision efficiency decreases with increasing $\mathrm{RH}_{\mathrm{w}}$ due to thermophoresis, a $\mathrm{RH}_{\mathrm{w}}$ dependence of contact nucleation indicates that the freezing efficiency upon collision is secondarily sensitive to $\mathrm{RH}_{\mathrm{w}}$.

Since the used kaolinite particles are polydisperse (from $0.3 \mu \mathrm{m}$ to $2.5 \mu \mathrm{m}$ in diameter) it could be that the largest particles were responsible for the observed freezing events in Svensson et al. (2009). If this is the case, the phoretic forces are of minor importance. The uncertainties in the reported freezing efficiencies in Svensson et al. (2009) can be reduced if experimental collision efficiencies are determined. Additionally, if monodisperse aerosol particles are used and 


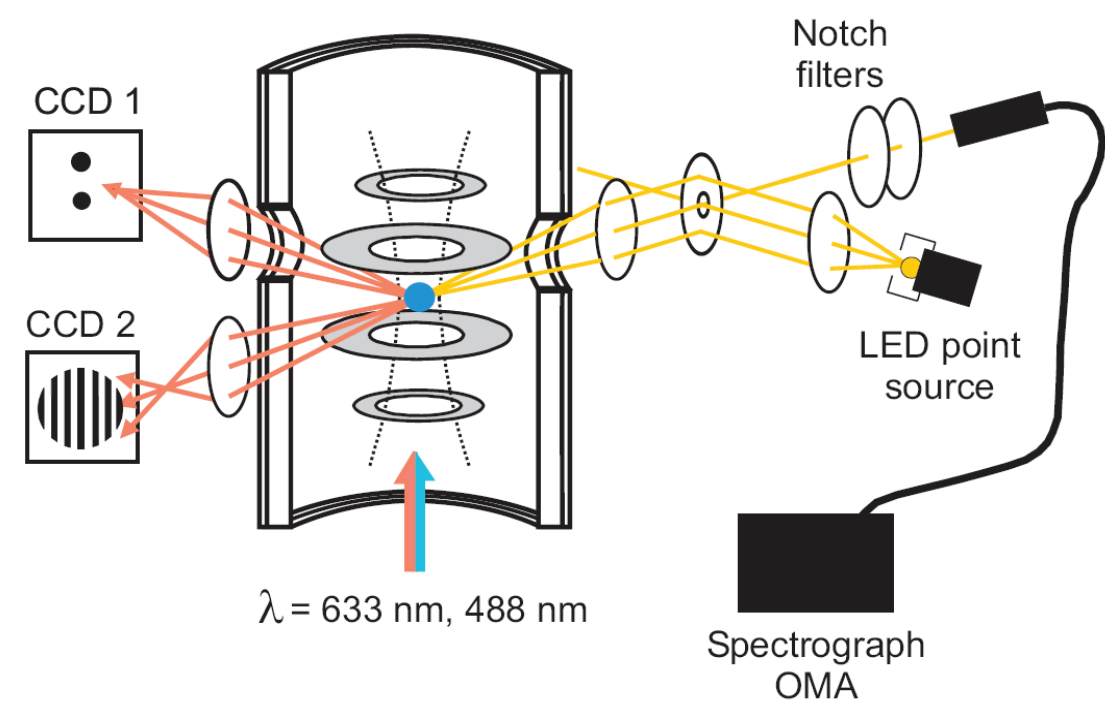

Fig. 8. Schematic with the electrodynamic balance experimental setup (Duft and Leisner, 2004a; Zardini et al., 2006).

droplet evaporation is controlled and measured, it will be possible to quantitatively confirm the dependence of contact nucleation on $\mathrm{RH}_{\mathrm{w}}$.

Hoffmann et al. (2013b) reported the FE of kaolinite and hematite, whereas Hoffmann et al. (2013a) investigated the FE of illite. They were able to measure the experimental collection efficiency which allowed them to quantitatively determine the FE for each material and particle size. The kaolinite FE values found by Hoffmann et al. (2013b) differ from those of Svensson et al. (2009). Svensson et al. (2009) found that kaolinite is able to nucleate ice at temperatures as high as $267 \mathrm{~K}$ (at humid conditions) which is $27 \mathrm{~K}$ higher than the observations made by Hoffmann et al. (2013b). However, this difference is substantially reduced (to $7 \mathrm{~K}$ ) when comparing the "dry conditions" data of Svensson et al. (2009) with Hoffmann et al. (2013b)'s data. The above-mentioned difference could be attributed to the polydisperse aerosol particles used by Svensson et al. (2009) which are in contrast with the $550 \mathrm{~nm}$ particles (in diameter) used in Hoffmann et al. (2013b)'s study.

Hoffmann et al. (2013b) and Hoffmann et al. (2013a) found a temperature and particle size dependence when using hematite and illite. Figure 9 clearly shows how FE increases with increasing the IN size. Additionally, the illite data nicely shows that ice nucleation due to contact freezing takes place at warmer temperatures when the particle size is increased. These observations support the contact freezing mechanisms proposed by Cooper (1974) and Fukuta (1975a).

\subsection{Cloud chambers}

There are different types of cloud chambers which are able to study the heterogeneous freezing modes independently and/or more than one mode at the same time. In this section the NCAR counter, the Colorado State University (CSU) isothermal cloud chamber, the thermal diffusion chamber and the collision ice nucleation chamber (CLINCH) are described with their corresponding results. Advantages of flow chambers are continuous flows and known residence times. It is possible to divide those instruments in two different categories, mixing cloud chambers and continuous flow cloud chambers.

\subsubsection{Mixing cloud chambers}

The NCAR ice nucleus counter is a mixing chamber which was originally built at the National Center for Atmospheric Research (NCAR, Langer et al., 1967); however, new chambers of the same type were built afterwards (e.g., Langer, 1973; Super et al., 2010). The NCAR ice nucleus counter is typically operated as follows. Haze particles, aerosol particles and/or $\mathrm{CCN}$ are combined with a humid air mass $\left(\mathrm{RH}_{\mathrm{w}} \approx 80 \%\right)$ at room temperature. The air stream with the particles is placed at the top of the chamber where its temperature is gradually reduced while the introduced particles are activated as the flow descends downward through the chamber (Langer, 1973). Langer et al. (1978) modified the standard NCAR counter to investigate immersion and contact freezing. This modification allows the injection of new particles which can be tested as IN. The particles are introduced in the bottom section of the chamber to interact with the activated cloud droplets at the desired temperature. The chamber wall temperatures are controlled by a cooling system. An acoustic sensor was used to detect ice at the exit of the counter. The currently available NCAR counters do not have the modification conducted by Langer et al. (1978).

The NCAR ice nucleus counter studies basically focused on submicron $(<150 \mathrm{~nm})$ AgI particles. In these studies, Brownian motion was the dominant dynamical force responsible for moving the aerosol particles towards the water 


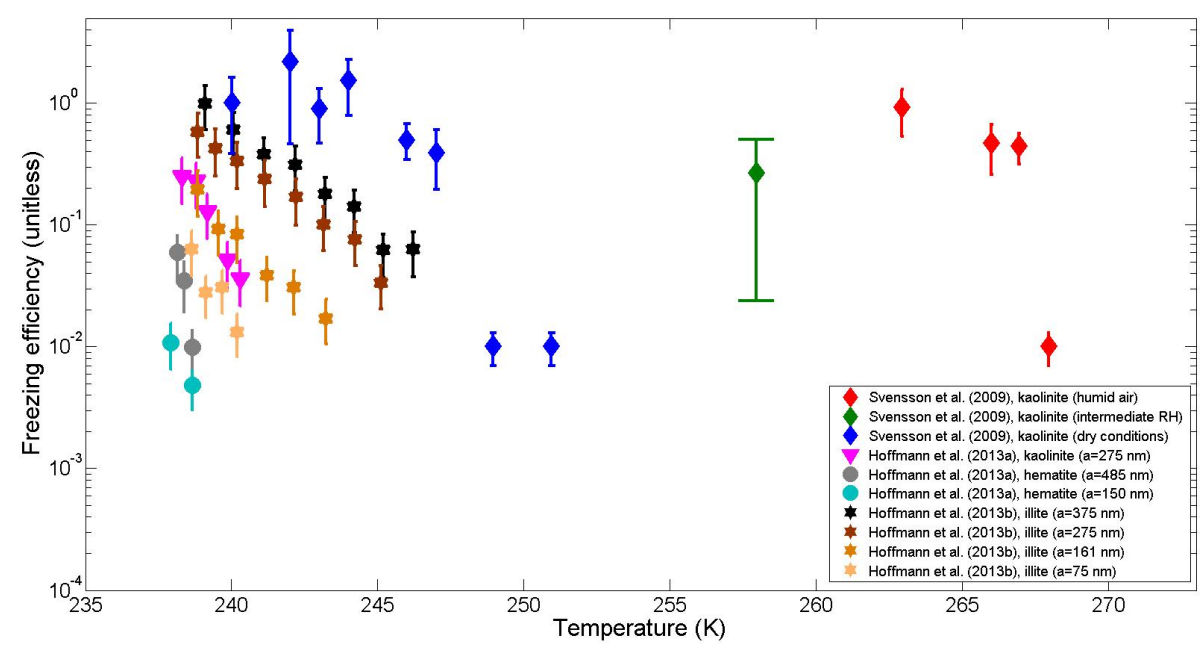

Fig. 9. Experimental freezing efficiencies (FE) of several materials obtained with an EDB. The red, green and blue diamonds represent the kaolinite experiments (polydisperse aerosol particles) from Svensson et al. (2009) at high, intermediate and low relative humidity with respect to water. The purple triangles and the colored circles represent the kaolinite and hematite results from Hoffmann et al. (2013b), respectively. The black, brown, dark yellow and orange stars represent the illite FE for 375, 275, 161 and $75 \mathrm{~nm}$, respectively (Hoffmann et al., 2013a).

drops. Langer et al. (1978) determined the freezing probabilities of AgI particles using the mathematical expression from Sax and Goldsmith (1972). They found that the freezing probabilities increased with decreasing temperature from $259 \mathrm{~K}$ to $253 \mathrm{~K}$. In addition, an aerosol particle size effect was clearly observed. Particles smaller than $0.02 \mu \mathrm{m}$ were not active, whereas for particles larger than $0.02 \mu \mathrm{m}$ the freezing probability increased with increasing particle size.

A static isothermal chamber with much longer residence times than the NCAR counter is the CSU isothermal cloud chamber (ICC). In the ICC, the cloud droplets were generated using an ultrasonic nebulizer and then transferred to a stand tube $(10 \mathrm{~cm}$ in diameter) to get into thermal equilibrium with the filtered cooled air before the cloud is discharged into the chamber (960 L) (Grant and Steele, 1966). Non-hygroscopic aerosol injected into the chamber with dry air and mixed quickly through the chamber volume will collide with drops if no other nucleation mechanism occurs. In the ICC, ice formation is monitored in time and particle coagulation is prevented by a dilution procedure (DeMott et al., 1983; DeMott, 1995).

DeMott et al. (1983) observed that the contact freezing efficiency was very high for the AgI-type ice nuclei examined at temperatures of $257 \mathrm{~K}$ and higher in agreement with Langer et al. (1978). They also found a clear pseudofirst-order dependence of ice nucleation by AgI aerosols on droplet concentrations and aerosol size. With the help of the isothermal chamber and the CSU expansion chamber, DeMott (1995) was able to determine that the freezing rates for contact freezing were higher than for the other three heterogeneous freezing modes.

\subsubsection{Continuous flow cloud chambers}

Another cloud chamber type is the thermal diffusion chamber. These chambers have been widely used to investigate the ice nuclei abilities of aerosol particles in different heterogeneous freezing modes and homogeneous freezing (Schaller and Fukuta, 1979; Hussain and Saunders, 1984; Tomlinson and Fukuta, 1985; Rogers, 1988; Stetzer et al., 2008; Kanji and Abbatt, 2009). All of these devices, some with continuous flow and some not, use temperature gradients between ice-coated walls to expose aerosols to ice and water supersaturations. Schaller and Fukuta (1979) built the first thermal diffusion chamber that was able to study contact freezing. The instrument has a wedge-shaped design and consists of two flat plates covered with ice in order to produce saturation with respect to ice. The temperature of both chamber walls can be varied, with the top wall being warmer than the bottom wall. It is also possible to have a concentric cylindrical configuration with a vertical orientation of the chamber (Rogers, 1988). For contact freezing, haze particles were formed at subsaturated conditions with respect to water. Once the haze particles were formed, the IN were injected into the chamber to allow them to collide with the haze particles.

Schaller and Fukuta (1979) observed a very low rate of nucleation for AgI particles, which means that they are less efficient nucleating ice at high temperatures (between $267 \mathrm{~K}$ and $265 \mathrm{~K})$. However, these results may be specific to the type of used AgI particles. Metaldehyde was found to be a very good IN at these temperatures, forming three orders of magnitude more ice crystals as compared to the used AgI. It could be that the high efficiency was due to the electric-dipolar nature of metaldehyde, which increases the number of collisions due to electroscavenging. Unfortunately, metaldehyde was 


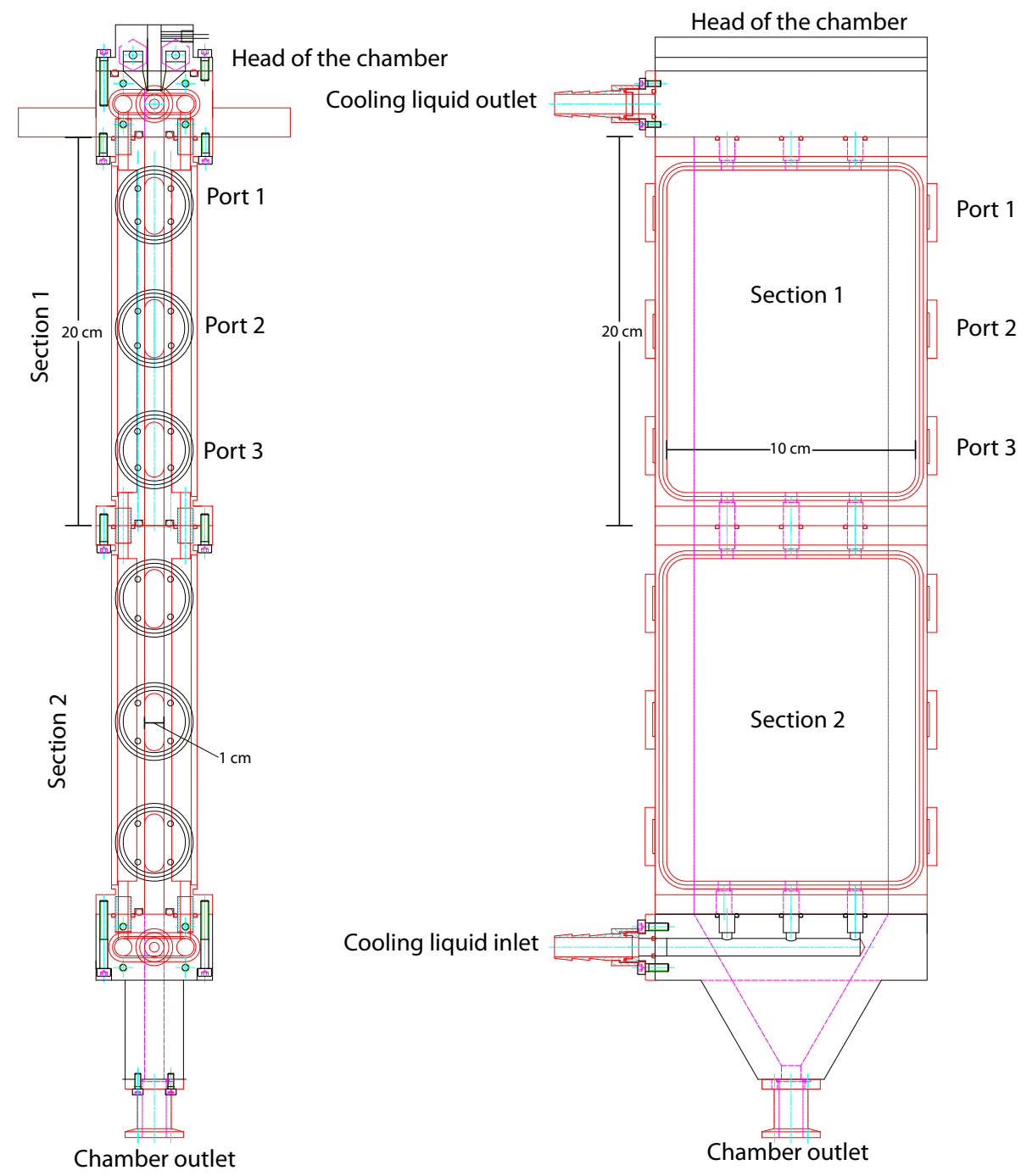

Fig. 10. Schematic with the CLINCH experimental setup; (left) side view and (right) front view of the instrument (Ladino, 2011).

not used in the subsequent contact freezing studies to confirm these observations. Note that collisions were with small haze droplets that are not diluted cloud droplets. Therefore, it is possible that the IN abilities of the tested aerosol particles were influenced by the solute.

The latest cloud chamber built is CLINCH (Ladino et al., 2011b). It is a continuous flow chamber which consists of two vertical parallel plates with lengths that can be varied between 20 and $80 \mathrm{~cm}$ as shown in Fig. 10. CLINCH uses a droplet generator to inject a series of droplets (with a variable frequency) at the top of the chamber. The aerosol particles enter the chamber at the head from both sides with an air flow. Aerosol particles can interact with the liquid droplets at a constant temperature and humidity in the volume between these plates. Both plates have the same temperature which is controlled with a cryostat. An Ice Optical DEtector (IODE) is used to distinguish between liquid droplets and ice crystals by depolarization (Nicolet et al., 2010). CLINCH is able to perform experiments on contact freezing varying the droplet size, particle size, IN type, aerosol particle concentration, residence time and temperature at ice saturation relative humidity.

Ladino et al. (2011b) studied the effect of the IN size and the aerosol particle concentration on the frozen fraction using kaolinite particles and cloud droplets of $12.7 \mu \mathrm{m}$ in radius. The left panel in Fig. 11 shows that the onset freezing temperature (defined when $3 \%$ of the droplets freeze) slightly increases with increasing the IN size. Although the authors observed a small difference in the onset freezing values, there is not a significant difference between the two tested IN sizes. This is in contrast with the observations made by Langer et al. (1978) and DeMott (1995) who found a particle size influence when using $\mathrm{AgI}$ and $\mathrm{AgI}-\mathrm{AgCl}$ particles and will be investigated further. Based on the CNT an increase in the surface area increases the probability to have more active sites 

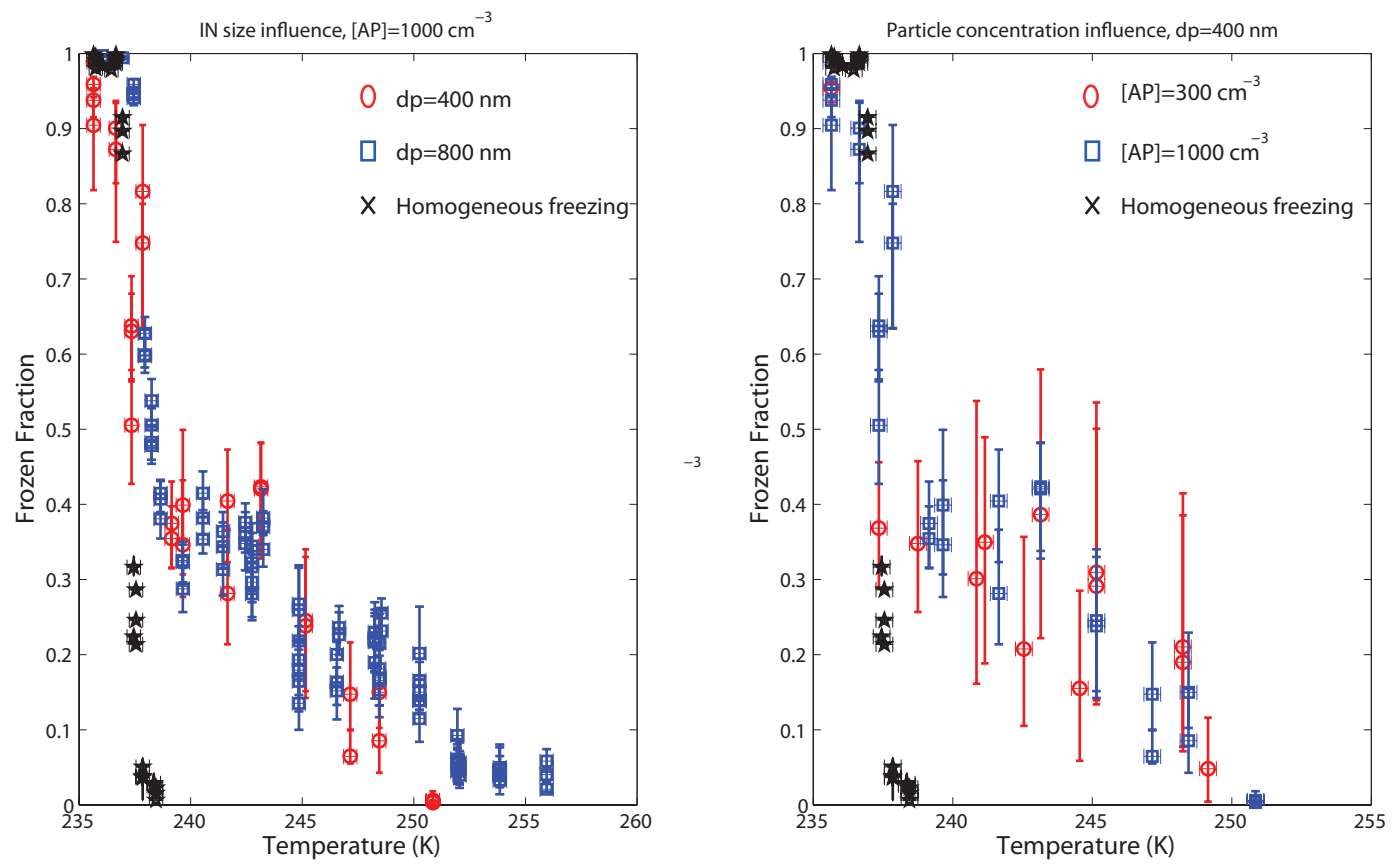

Fig. 11. Experimental frozen fraction on contact freezing as a function of temperature conducted in CLINCH. The cloud droplets have a residence time of $5 \mathrm{~s}$. The left panel shows the comparison of two different particle sizes and the right panel the comparison of two different aerosol particle concentrations. The black stars represent the homogeneous freezing data. $d p$ refers to the aerosol particle diameter and [AP] to the aerosol particle concentration.

at which the ice germ can form, which results in higher onset freezing temperatures (Pruppacher and Klett, 1997).

The right panel in Fig. 11 shows the frozen fraction for two different aerosol particle concentrations. Keeping the CE constant for a drop-particle size pair, the number of particles within the droplet's sweep-out volume and the number of collected particles by the droplets will increase if the aerosol particle concentration is increased. It results in a larger number of potential IN and active sites interacting with the droplets, causing a larger number of nucleated ice crystals. Nevertheless, differences in freezing fractions when using $300 \mathrm{~cm}^{-3}$ or $1000 \mathrm{~cm}^{-3}$ kaolinite particles were surprisingly small and will be further investigated.

In CLINCH the droplet size is measured accurately at the top section, however its size along the chamber and at the bottom section is uncertain since the droplets shrink due to evaporation. The droplet size is a key parameter when determining the collision efficiency, which in turn is important to determine the freezing efficiency of contact freezing. This is the reason for the high and uncertain freezing efficiencies reported from CLINCH (Ladino et al., 2011b). More research in this direction is needed.

\subsection{Freezing efficiency results inter-comparison}

In the above sections it was shown that the frozen fraction can be experimentally determined by the different instrumentation. In some cases the freezing efficiencies can also be calculated based on the instrument and available information. However, the reported freezing efficiencies are experiment-dependent. Because kaolinite has been extensively studied with different instrumentation, it was chosen to inter-compare the freezing efficiencies obtained with the wind tunnel, the cold plate technique, EDB and CLINCH. However, the chemical composition of the used kaolinite particles may be different since kaolinites from different sources have different mineralogical compositions as shown by Atkinson et al. (2013). The experiment-dependent kaolinite freezing efficiencies are summarized in Fig. 12.

Although Pitter and Pruppacher (1973) did not calculate/report the freezing efficiency of their wind tunnel experiments, we used the provided data to calculate their corresponding freezing efficiencies based on some assumptions in order to investigate the role of the aerosol particle concentration on the freezing efficiencies. The three $N_{\text {coll }}$ scenarios from the wind tunnel data demonstrate the high variability and sensitivity of these calculations. The dependence of freezing efficiency on $\mathrm{RH}_{\mathrm{w}}$ reported in Svensson et al. (2009), particle size reported in Bunker et al. (2012); Hoffmann et al. (2013b, a) and the two droplet size in Ladino et al. (2011b) is obvious.

Figure 12 also shows theoretical calculations (solid color lines) of $N_{\mathrm{g} \text {,contact }}$ using Eq. (6) following the procedure described in Hoose et al. (2010). These calculations were conducted for particles with a diameter of $500 \mathrm{~nm}$, a contact 


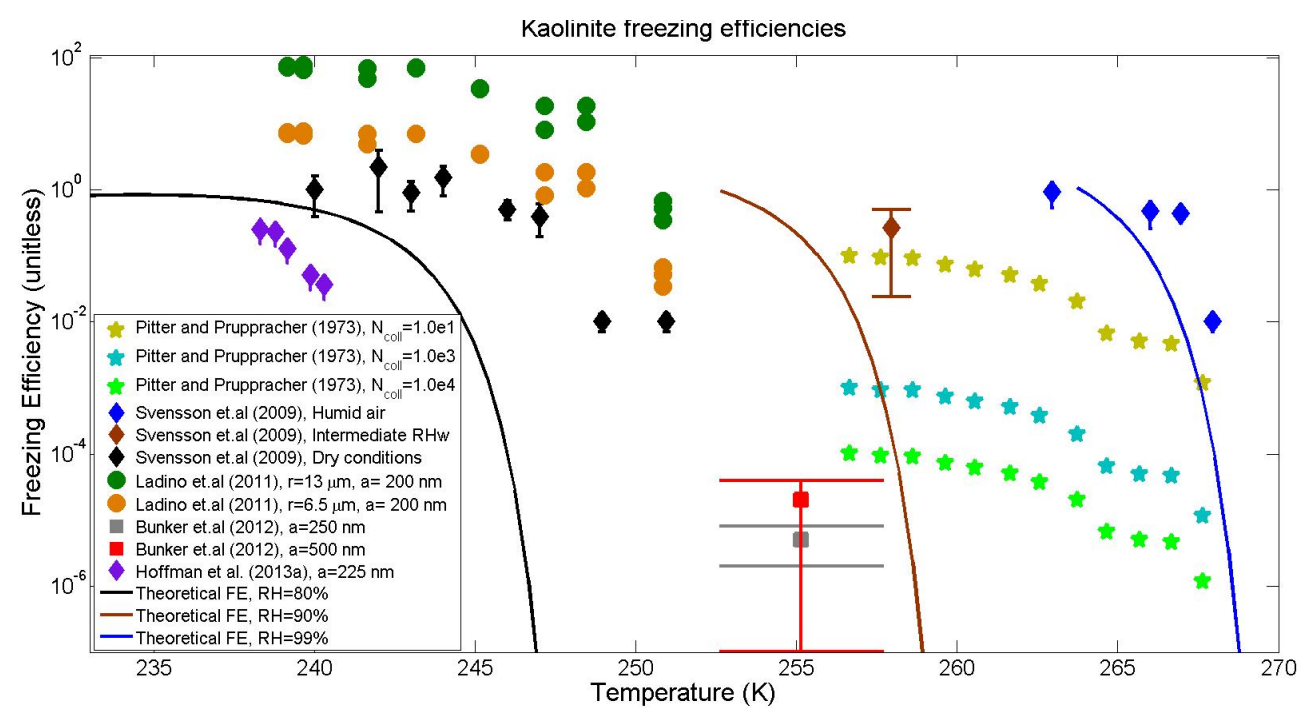

Fig. 12. Comparison of the available kaolinite freezing efficiencies due to contact nucleation as a function of temperature from different instrumentation. In those studies that reported frozen fractions we have calculated the freezing efficiency, assuming different values for $N_{\text {coll }}$. The stars represent the wind tunnel data with different assumptions for the unknown parameter $N_{\text {coll }}$ (Pitter and Pruppacher, 1973), whereas the diamonds, circles and squares depict the data from the EDB (Svensson et al., 2009; Hoffmann et al., 2013b), CLINCH (Ladino et al., 2011b) and the cold plate data (Bunker et al., 2012), respectively.

angle of $12.7^{\circ}$ and a $\Delta \mathrm{G}$ of $-0.621 \times 10^{-20} \mathrm{~J}$. Note that $N_{\mathrm{g} \text {,contact }}$ is equivalent to $F E$. The theoretical calculations show that ice forms at higher temperatures with increasing $\mathrm{RH}_{\mathrm{w}}$. This is in agreement with the observations made by Svensson et al. (2009). Note that the relative humidities for the dry, intermediate and humid conditions of the experiments conducted by Svensson et al. (2009) were not reported. At high $\mathrm{RH}_{\mathrm{w}}$ 's, the theoretical increase of $F E$ with temperature is very steep and it requires less than $5 \mathrm{~K}$ to move from $1.0 \times 10^{-5}$ to 1.0 . This is in agreement with the humid air data from Svensson et al. (2009) but is in contrast with the experimentally derived $F E$ 's from Pitter and Pruppacher (1973) data. At $\mathrm{RH}_{\mathrm{w}}$ of $80 \%$ around $10 \mathrm{~K}$ are needed to obtain $F E=1$ from the theoretical calculations. This temperature trend is closer to the trend reported by Pitter and Pruppacher (1973); Ladino et al. (2011b); Hoffmann et al. (2013a, b) and the dry data from Svensson et al. (2009). The discrepancies can be attributed to the different experimental conditions and to the assumptions made for the theoretical calculations. The large FE values reported by Ladino et al. (2011b) are the result of an overestimation of the droplet size in the CE calculations and due to the use of a laser with a circular profile in the IODE detector.

Even though the particle type (kaolinite) is the same in all four studies, the experimental conditions differ substantially. The IN efficiency of the kaolinite used by Bunker et al. (2012) was lower as compared to the other studies. The kaolinite source, the differences in droplet size, and sensitivities on determining the first freezing event could explain these discrepancies. It is possible that the used kaolinite samples have substantial differences in their chemical composition. The experimental differences and the high uncertainty in the collision rates are reflected in the calculated kaolinite freezing efficiency. These values differ by several orders of magnitude in the same temperature range, even when similar particle and droplet sizes are used. Although the comparison of the theoretical and experimental results is qualitative, it confirms how sensitive the determination of $F E$ is. That is why better designed experiments or inter-laboratory campaigns (i.e., experiments of contact freezing using different techniques with the same IN samples and aerosol particle concentration, $\mathrm{RH}_{\mathrm{w}}$ and droplet and particle sizes) are needed to validate the freezing efficiency of contact freezing that could be used in process and climate models.

\subsection{Contact freezing versus immersion freezing}

Roberts and Hallett (1968) and Niemand et al. (2012) investigated the fraction of active ice nuclei in the immersion freezing mode as a function of temperature. Roberts and Hallett (1968) used five clays and minerals, whereas Niemand et al. (2012) used five natural mineral dust samples. Both studies found that the fraction of active IN in this heterogeneous freezing mode is temperature dependent. Roberts and Hallett (1968) found that $\approx 50 \%$ of the tested particles were active at temperatures between $258 \mathrm{~K}$ and $248 \mathrm{~K}$. Niemand et al. (2012) reported that at $254 \mathrm{~K}$ and $246 \mathrm{~K}, 0.01 \%$ and $1 \%$ of the tested aerosol particles were active in the immersion freezing mode, respectively. In theory Niemand et al. (2012)'s data could be compared with the contact freezing 


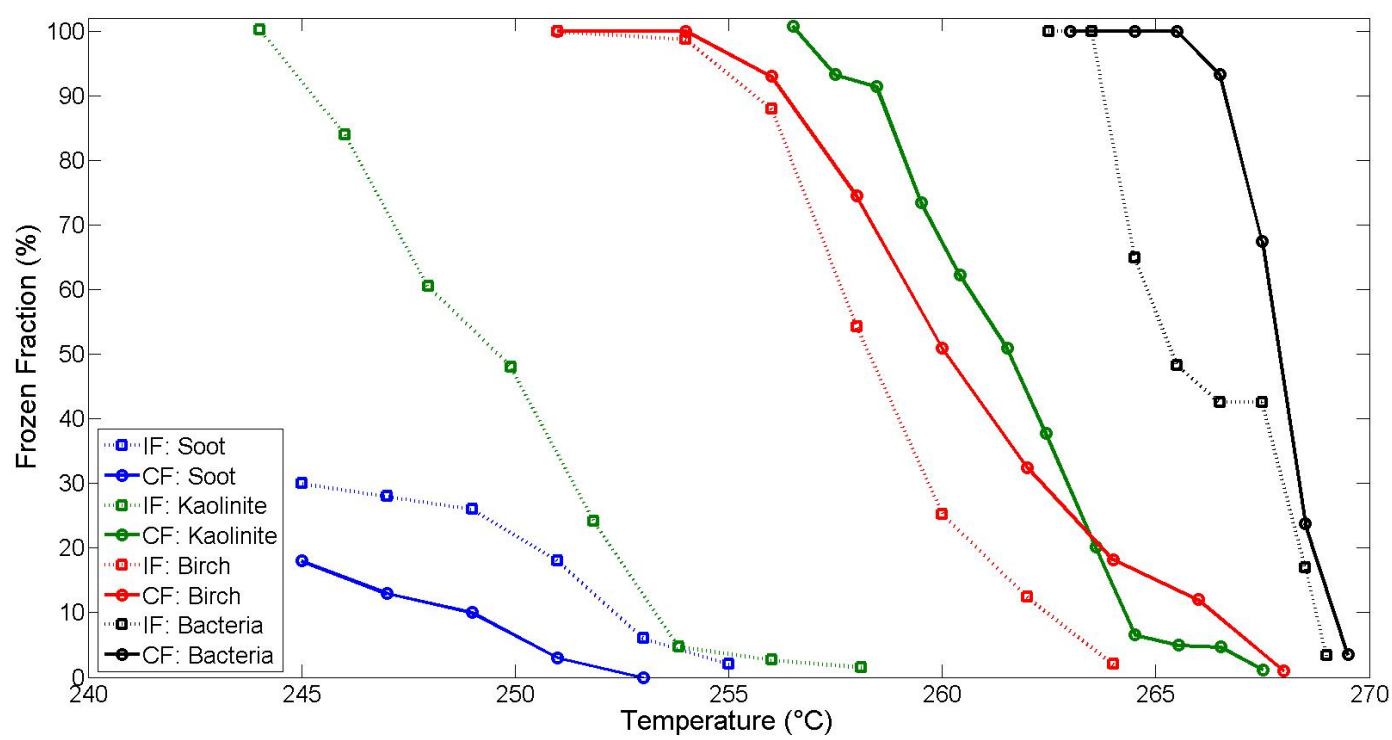

Fig. 13. Comparison of contact freezing (CF) and immersion freezing (IF) results as a function of temperature using different IN. All the experiments were conducted in a wind tunnel. The contact freezing and the immersion freezing experiments are represented by the solid (circles) and dotted (squares) lines respectively. The blue color represent the experiments done with soot particles, green with kaolinite, red with pollen and black with bacteria (Pitter and Pruppacher, 1973; Levin and Yankofsky, 1983; Diehl and Mitra, 1998; Diehl et al., 2002). Note that the collision rates are not accounted for in any of the presented results.

data from Fig. 12; however, this is not possible due to the limitations mentioned in the above section.

A direct qualitative and quantitative comparison between contact freezing and immersion freezing from experimental results has been done by Pitter and Pruppacher (1973); Levin and Yankofsky (1983); Diehl and Mitra (1998); Diehl et al. (2002); Ladino et al. (2011b); Shaw et al. (2005); Durant and Shaw (2005) and Fornea et al. (2009) using a wind tunnel, the CLINCH/IMCA, or the cold plate technique. The same particles were either immersed within a droplet (before or during the experiment) or put in contact with the droplet surface (mechanically or due to a flow). Langer et al. (1978), Schaller and Fukuta (1979), DeMott et al. (1983), and DeMott (1995) conducted experiments of the other heterogeneous freezing modes in addition to contact freezing in their cloud chambers. However, due to the large complexity in assigning an ice nucleation event to a specific mechanism they are not discussed here.

Figure 13 shows a qualitative comparison of contact vs. immersion freezing experiments conducted in a wind tunnel. Contact freezing occurs at higher temperatures than immersion freezing when bacteria, pollen or kaolinite particles were used. In these experiments, the numbers of ice crystals formed was typically higher than for immersion freezing at a given temperature. Only soot particles show the opposite behavior where immersion freezing was found to be more efficient than contact freezing. The difference between the two freezing modes for soot is however, much smaller than for kaolinite particles. Kaolinite particles show a difference in the onset freezing temperature of around $10 \mathrm{~K}$ whereas the other tested particles only show a difference of less than $4 \mathrm{~K}$.

Another qualitative comparison between these two modes was done by Ladino et al. (2011b). The contact freezing experiments were conducted in CLINCH, whereas the immersion freezing experiments used the immersion freezing chamber IMCA (Lüönd et al., 2010). This comparison is limited by having used different chambers and different droplet sizes, but used the same kaolinite particles of the same size, particle generator, size selection technique and detector. Figure 14 shows the results using two different particle sizes. Note that the number of ice crystals in CLINCH is limited by the number of collisions to a frozen fraction of 0.4. For both particle sizes $400 \mathrm{~nm}$ (left) and $800 \mathrm{~nm}$ (right) there is a small difference in the onset freezing temperature and in the frozen fraction being more pronounced for the $400 \mathrm{~nm}$ particles. This means that CLINCH/IMCA also qualitatively shows that contact freezing is initiated at higher temperature than immersion freezing. This comparison has a similar limitation as the one from the wind tunnel studies because the number of particles that collides with the droplet on average is below one, hence it is smaller than the single particle immersed within each droplet in the IMCA experiments. Furthermore the influence of the droplet size in CLINCH is not clear since it is shrinking, which changes its collision efficiency. This will be investigated further in the future.

Table 2 summarizes the quantitative comparisons between immersion and contact freezing from the experiments conducted with the cold plate technique. Two volcanic ash particles and two organic particles that behave like glasses were 

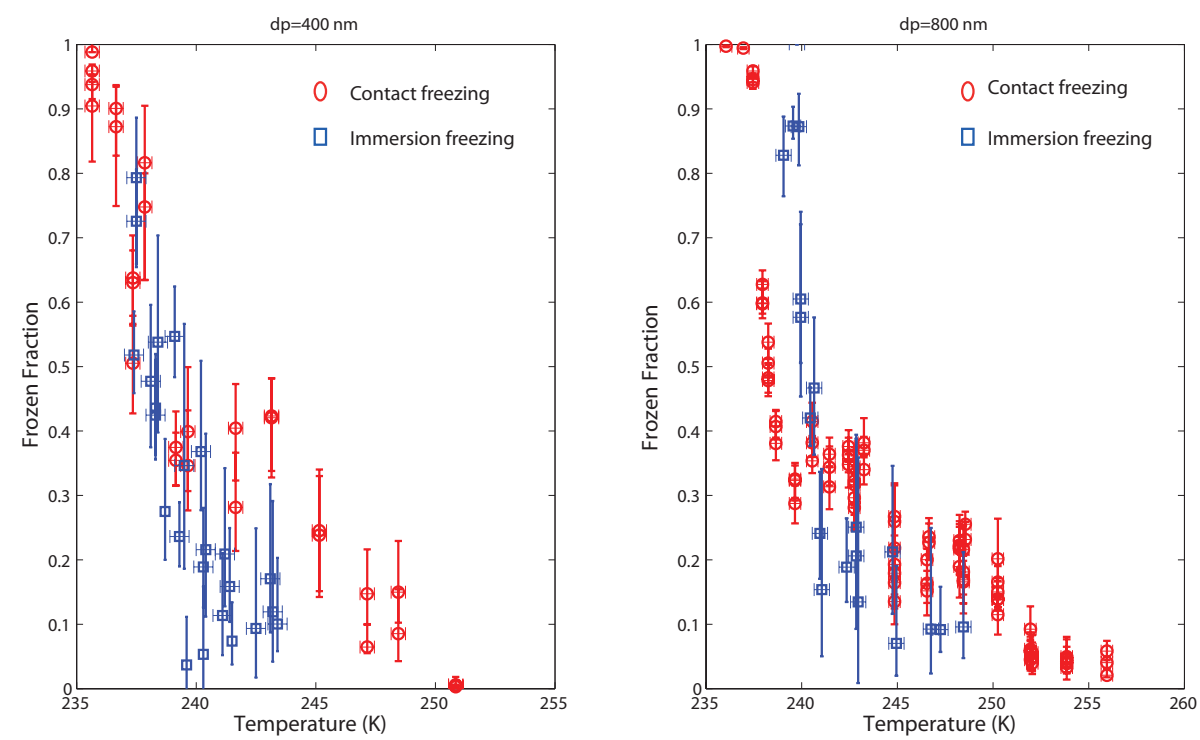

Fig. 14. Comparison of contact freezing and immersion freezing results for kaolinite particles. Red circles represent the contact freezing experiments for cloud droplets of $26 \mu \mathrm{m}$ (in diameter) with a residence time of $5 \mathrm{~s}$, whereas the blue squares represent the immersion freezing data with a droplet diameter of $6 \mu \mathrm{m} . d p$ refers to the aerosol particle diameter.

investigated. The differences in the onset freezing temperature vary between $3 \mathrm{~K}$ and $7 \mathrm{~K}$. The differences are consistent even if different cold plates and IN are used. All cold plate experiments were conducted using different particle and droplet sizes, which complicate the comparison of results from different authors. These experiments did not report the frozen fraction as they used a single droplet and a single aerosol particle.

The comparison between these two modes is more precise in the cold plate technique experiments as it uses one IN per drop in both contact and immersion freezing. However, this comparison can be improved if the IN surface area which enters in contact with the droplet (or the line length of the three-phase boundary according to the three-phasemodel in Sect. 2.3.4) is estimated and used instead of the number of particles. The aerosol particle surface area for immersion freezing experiments is constant over time, however, the surface area in the contact freezing experiments in the wind tunnel, EDB and CLINCH studies increases with time with the exception of cold plate technique studies where only one aerosol particle per drop was used. For the wind tunnel experiments it is unknown if the IN/drop ratio in contact and immersion freezing mode is comparable. The comparison with CLINCH is also not adequate, as their contact freezing experiments are not normalized to the number of collisions, whereas in IMCA the particle-droplet ratio is always one. However, if the shrinking droplet size from CLINCH is estimated accurately, a better calculation of $N_{\text {coll }}$ can be obtained and hence a normalization will be possible. Thus simultaneous comparable measurements of contact and immersion freezing are urgently needed.
As shown above, immersion freezing and contact freezing data are often compared to each other. However, a comparison between both modes is difficult because a number of parameters should be controlled or constrained. We suggest here a possible approach for the comparison of $N_{\mathrm{g}, \text { contact }}$ and $N_{\text {g,immersion }}$ (see Fig. 15).

The freezing efficiencies or the frozen fractions for both modes can only be directly compared, when droplets of one size are exposed to the same number of particles of the same size for the same time. The implications not only for experiments on both modes but also for natural clouds, in which contact freezing is possible, are as follows. Under pure immersion freezing conditions (all particles are immersed in droplets and each droplet contains only one particle) the droplet freezes after some time since the IN surface area in contact with the supercooled liquid is constant over time. In this setting the $\ln$ of the frozen fraction scales linearly with time and surface area of the IN at a given temperature (Murray et al., 2011; Hoffmann et al., 2013b; Knopf and Alpert, 2013):

$\ln \left(\frac{N_{\text {frozen }}(t)}{N_{\text {total }}}\right)=J_{\text {imm }}(T) \cdot S(t) \cdot t$,

where $J_{\mathrm{imm}}$ is the nucleation rate due to immersion freezing as a function of temperature $(T)$, and $S(t)$ the total area of immersed particles as a function of time $(t)$.

Under pure contact freezing conditions, once an IN collides with a supercooled droplet it can cause freezing of the droplet due to contact freezing. If this does not happen, we assume that the IN gets immersed into the droplet and can then act as an immersion freezing nucleus. If immersion freezing does not cause the droplet to freeze under 

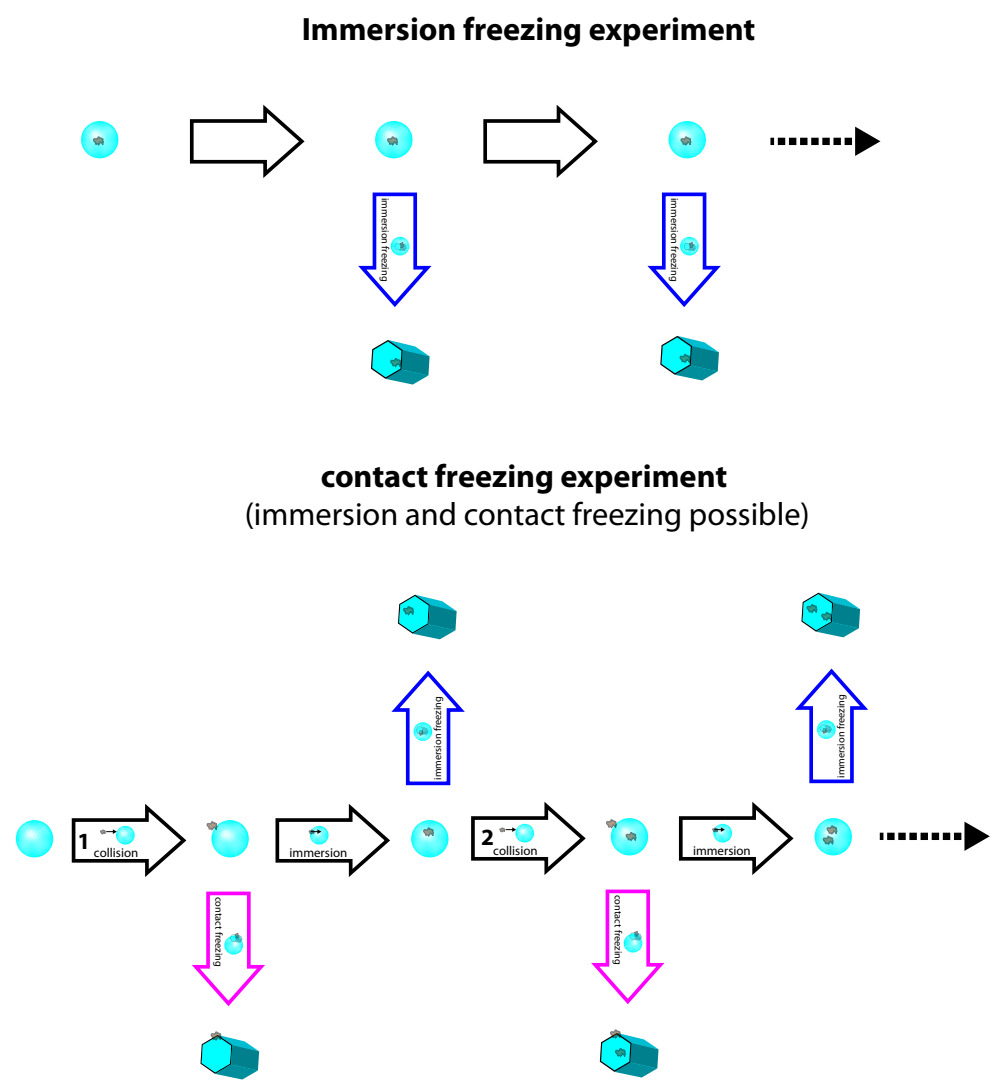

Fig. 15. Schematic of a typical contact and immersion freezing experiment. For details refer to the main text.

the prevailing conditions, another IN can collide with the droplet. Again, either contact freezing can take place, or immersion freezing can occur after the particle is immersed in the droplet. This cycle continues until the droplet freezes by one of the two processes. Hence, contact freezing is constant over time (as is the collision rate) assuming a constant particle flux and similar aerosol particle size since the collision efficiency varies as a function of both parameters, while the number (and thus the surface area) of immersed particles in a droplet increases linearly with time, causing the immersion freezing process to be a function of time squared. To unambiguously determine which freezing process causes the droplets to freeze requires studying the time-dependence of the freezing process (Hoffmann et al., 2013b):

$\ln \left(\frac{N_{\text {frozen }}(t)}{N_{\text {total }}}\right)=\left[J_{\mathrm{imm}}(T) \cdot S(t) \cdot t\right]+\left[\mathrm{FE}(T) \cdot n_{\mathrm{c}} \cdot t\right],(10)$ $=\left[J_{\mathrm{imm}}(T) \cdot S_{\mathrm{p}} \cdot n_{c} \cdot t^{2}\right]+\left[F E(T) \cdot n_{\mid t e x t c} \cdot t\right]$,

where $S_{\mathrm{p}}$ is the aerosol particle surface area, and $n_{\mathrm{c}}$ the collision rate $\left(N_{\text {coll }} / t\right)$. Based on the evaluation of Hoffmann et al. (2013b)'s experiments according to Eq. (11), they found that they indeed observed contact freezing in their experiments.

\subsection{Parameterizations}

In order to consider contact freezing in numerical models, several parameterizations were derived for the IN concentrations (Young, 1974b; Meyers et al., 1992; Phillips et al., 2008; Morrison et al., 2008; Hoose et al., 2010). Because the wind tunnel and the CLINCH experiments yield a frozen fraction but not the number of IN, we compare the experimental wind tunnel and CLINCH data with the parameterized frozen fractions from Diehl et al. (2006) in Fig. 16. Good agreement between the wind tunnel data and mineral dust, bacteria and pollen is achieved because these data were used to obtain the parameterization. However, soot in the wind tunnel initiated freezing at much colder temperatures than the parameterization suggests. This is because the soot parameterization is based on the data by Gorbunov et al. (2001). It is however questionable if the freezing of soot in the Gorbunov et al. (2001) study is really due to contact nucleation or rather due to deposition nucleation. The much colder freezing temperatures of the soot measured by Diehl and Mitra (1998) are thought to be caused by an organic coating of the particles emitted as a byproduct of the used kerosene burner (Diehl, personal communication). The kerosene soot burner data show a freezing onset and increase of frozen fraction with decreasing temperature that is comparable to what is 


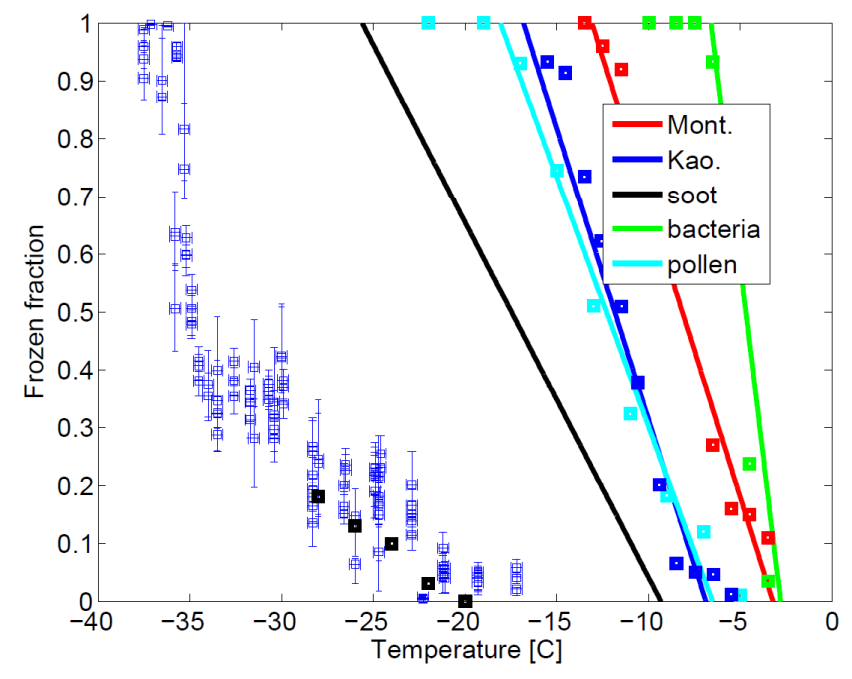

Fig. 16. Comparison of contact freezing frozen fractions obtained from wind tunnel studies (thick squares) using kaolinite (blue) and montmorillonite (red) (Pitter and Pruppacher, 1973), soot (black) (Diehl and Mitra, 1998), pollen (light blue) (Diehl et al., 2002) and bacteria (green) (Levin and Yankofsky, 1983) and CLINCH (thin squares with error bars) using kaolinite (Ladino et al., 2011b) as compared with the parameterized contact freezing frozen fractions by Diehl et al. (2006) (solid lines).

found for two different sizes of kaolinite using CLINCH. Kaolinite in CLINCH freezes at much colder temperatures than in the wind tunnel. This range in freezing onset and increase of frozen fraction with decreasing temperature shows the uncertainty in the data and will translate in an equally large uncertainty in the parameterization of the frozen fraction.

\section{Conclusions}

There is experimental evidence for contact freezing to act as proposed by Cooper (1974), Durant and Shaw (2005) and Djikaev and Ruckenstein (2008), however it is still unclear why the available laboratory results indicate that contact freezing is the most efficient ice nucleation mode. More and better controlled experiments are needed to validate the proposed hypotheses by Cooper (1974) and Fukuta (1975a) which so far are the most promising ideas. Both theories are based on the CNT and include key parameters partially proven by laboratory experiments such as water adsorption on the particle surface, $\mathrm{RH}_{\mathrm{w}}$ and IN size. Additionally, the evaporation freezing pathway introduced by Durant and Shaw (2005) could take place within mixed-phase clouds under subsaturated conditions.

Laboratory experiments designed to specifically quantify contact freezing indicate that contact freezing initiates ice formation at warmer temperatures than other heterogeneous freezing modes. However, contact freezing is limited by the collision efficiency and therefore its efficiency in the atmosphere is not known. A difference of around $1-10 \mathrm{~K}$ in the onset freezing temperatures and in the number of formed ice crystals at a given temperature between contact and immersion freezing was found when using the wind tunnel and the CLINCH/IMCA flow chambers with different IN. However, these comparisons are not conclusive due to several limitations in both systems. Experiments conducted in the mixing chamber also showed a clear difference between contact freezing, condensation/immersion freezing, and deposition nucleation. A difference of around 3-7 K was found in the onset freezing temperatures when using a static cold plate with different volcanic ash particles. Based on the laboratory results from the static cold plate which are quantitative, contact freezing is clearly distinguished from the other heterogeneous freezing modes and it is so far the most efficient pathway to nucleate ice crystals.

The atmospheric IN concentrations are much smaller than the values used in the laboratory experiments. Additionally, the laboratory experiments could be biased by the use of $\mathrm{RH}_{\mathrm{w}}$ below $100 \%$, which favors the collisions between aerosol particles and cloud droplets due to thermophoresis. Therefore, the atmospheric relevance of contact freezing is not yet clear. A quantitative calculation of the frozen fraction is needed to determine the maximum freezing efficiencies. Disagreements with theoretical collection rates remain and need to be investigated in future. Most of the experimental studies did not report the collision rates and therefore give only experiment-specific frozen fractions but no experimentindependent freezing efficiencies (with the exception of the data reported by Hoffmann et al., 2013b and Hoffmann et al., 2013a). Once collision rates are known, the uncertainty in the freezing efficiency calculation will be substantially reduced. It will allow an intercomparison between data sets from different experiments and an extrapolation of the laboratory results to atmospheric conditions is possible. This especially includes more experiments with cloud droplets and monodisperse submicron aerosol particles, taking into account the aerosol particle concentration and $\mathrm{RH}_{\mathrm{w}}$ are needed.

The static cold plate studies suggest that the difference in the temperature at which an ice germ forms in the contact and immersion freezing mode could be caused by the interaction between the different phases but does not involve a collision energy. However, wind tunnel and flow chamber experiments where collisions take place also show a difference between these two heterogeneous freezing modes. It is thus difficult to conclude if the ice germs form at higher temperatures during contact freezing than immersion freezing due to the collision (IN-droplet) or due to the phase interactions or if it is a combination of both factors. There are some indications for both theories but they are not proven as the experimental data have some limitations. In the static cold plate experiments large particles were used, thus the surface area of the particles which comes in contact with the droplets is much larger than the submicron particles which were used in 
wind tunnel studies and in CLINCH. In cases where collisions are present, the surface area that comes in contact with the droplet is not known.

In a real cloud, more than one freezing mechanism can take place at the same time. It will be interesting to perform experiments where a single IN is immersed in a liquid droplet and thereafter more IN are injected that collide with the droplet/IN system to simulate the real competition between immersion and contact freezing within a mixed-phase cloud. In addition to it, the inclusion and control of growing and shrinking of droplets to alter the collision frequency will increase the atmospheric relevance of these experiments. This type of experiment will tell us if contact freezing matters in this scenario. Mixing chambers like the NCAR ice nucleus counter or the CSU-CIC can be perfectly adjusted to do that.

New instrumentation is needed where the atmospheric conditions can be reproduced as closely as possible in order to increase the usefulness of the produced data. New instrumentation should measure and control the important parameters for contact freezing $\left(\mathrm{RH}_{\mathrm{w}}, a, r, N_{\mathrm{a}}\right)$. Additionally, field measurements on contact freezing are urgently needed since these studies are very scarce (e.g., Davis and Auer, 1972). The conditions at which contact freezing takes place in a natural environment are needed to estimate its atmospheric relevance. To assess whether and where contact nucleation is a possible process, a field study similar to the NASA African Monsoon Multidisciplinary Analyses (NAMMA) experiment is needed. One limitation to perform field measurements is to overcome the low collection rates. The collection rates could be enhanced if the aerosol concentration and the residence time are increased. The aerosol concentration can be increased with the help of an aerosol particle concentrator and/or a counter flow virtual impactor (it is commonly used to separate cloud droplets or ice crystals from interstitial aerosols but it is also possible to use it as an aerosol concentrator; Slowik et al., 2011). Field measurements will allow us to validate the laboratory experiments and their data will be very valuable for validation of numerical models (cloud resolving, regional and global climate models). Field measurements are also important because they include dynamical effects such as organized updraft and downdraft motions, wind shear, turbulence and entrainment, which are commonly neglected in the laboratory studies. The addition of those dynamical effects on the contact freezing laboratory experiments will allow us to better mimic this heterogeneous freezing mode.

Almost all previous comparisons between immersion freezing and contact freezing were done with the aim to study the IN ability in both modes and to infer which mode is more efficient. However, an accurate direct comparison is not possible (or has not yet been done) because even when using the same IN and the same particle size the experimental conditions are different. The number of particles within or in contact with the droplet in both modes is different. Assuming that the ratio particle/droplet is the same, the comparison is still not completely valid because in the immersion mode the entire IN surface is immersed, therefore the whole IN plays a role in that case. In contrast, in contact freezing only a part of the IN surface is in contact with the droplet, therefore only a small part of the IN is responsible for freezing. In order to directly compare and validate the available instrumentation, it would be interesting to perform a contact nucleation intercomparison where all experiments use the same chemical composition and particle size at a defined temperature range.

Answering the following key questions will help us to understand the impact of contact freezing on cloud glaciation and hence on the hydrological cycle and on the radiative properties of clouds. Some of these points were already highlighted by Vali (1985) and Meyers et al. (1992) but they remain open and/or uncertain:

- Which is the most appropriate or representative theory to explain ice formation due to contact freezing from a microscopic perspective?

- Is the collision energy crucial to initiate freezing or is it purely an air-water inter-phase effect?

- Is contact freezing time dependent and thus a stochastic process?

- Does the particle stick on the droplet surface as found by Gokhale and Goold Jr (1968) or does the particle get partially or completely immersed into the droplet? If the latter, what are the particle penetration rates?

- How many collisions are needed to trigger the freezing of cloud droplets due to contact freezing? What are the freezing efficiencies of different INs in contact freezing mode?

- Do parameters other than particle type, aerosol size, temperature, aerosol particle concentration and time influence contact freezing? Does droplet size matter?

- Why is contact freezing more efficient at nucleating ice than the other freezing modes?

- Is contact freezing an especially effective mechanism also in real atmospheric cloud situations?

Acknowledgements. The authors would like to thank Zamin Kanji, Felix Lüönd, Cedric Chou, Andre Welti, and Vivek Sant for their valuable contribution during the interesting discussions. We

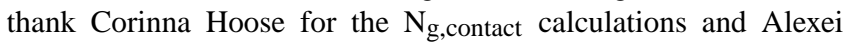
Kiselev for sharing his ideas, which are indicated in Fig. 15 and the corresponding formulas. We also enormously thank Daniel Knopf and the reviewers for helping us to considerably improve the manuscript. This work was supported by the Swiss National Foundation (SNF) with the following projects: 200021-107663/1 and 200021-127275.

Edited by: D. Knopf 


\section{References}

Abbatt, J., Benz, S., Cziczo, D., Kanji, Z., Lohmann, U., and Möhler, O.: Solid ammonium sulfate aerosols as ice nuclei: A pathway for cirrus cloud formation, Science, 313, 1770-1773, 2006.

Andronache, C., Gronholm, T., Laakso, L., Phillips, V., and Venalainen, A.: Scavenging of ultrafine particles by rainfall at a boreal site: observations and model estimations, Atmos. Chem. Phys., 6, 4739-4754, 2006,

http://www.atmos-chem-phys.net/6/4739/2006/.

Ansmann, A., Mattis, I., Müller, D., Wandinger, U., Radlach, M., Althausen, D., and Damoah, R.: Ice formation in Saharan dust over central Europe observed with temperature/humidity/aerosol Raman lidar, J. Geophys. Res., 110, D18S12, 2005.

Atkinson, J. D., Murray, B. J., Woodhouse, M. T., Whale, T. F., Baustian, K. J., Carslaw, K. S., Dobbie, S., O?Sullivan, D., and Malkin, T. L.: The importance of feldspar for ice nucleation by mineral dust in mixed-phase clouds, Nature, 498, 355-358, 2013.

Auer Jr, A. H.: Observations of ice crystal nucleation by droplet freezing in natural clouds., J. Atmos. Sci., 28, 285-290, 1971.

Beard, K.: Experimental and numerical collision efficiency for submicron particles scavenged by small rain drops, J. Atmos. Sci., 31, 1595-1603, 1974.

Beard, K. and Pruppacher, H.: A Determination of the Terminal Velocity and Drag of Small Water Drops by Means of a Wind Tunnel., J. Atmos. Sci., 26, 1066-1072, 1969.

Bunker, K., China, S., Mazzoleni, C., Kostinski, A., and Cantrell, W.: Measurements of ice nucleation by mineral dusts in the contact mode, Atmos. Chem. Phys. Discuss, 12, 20 291-20 309, 2012.

Chen, J., Hazra, A., and Levin, Z.: Parameterizing ice nucleation rates using contact angle and activation energy derived from laboratory data, Atmos. Chem. Phys, 8, 7431-7449, 2008.

Cooper, W.: A possible mechanism for contact nucleation, J. Atmos. Sci., 31, 1832-1837, 1974.

Cooper, W.: Reply to comments on: A possible mechanism for contact nucleation, J. Atmos. Sci., 32, 2373-2375, 1975.

Croft, B., Lohmann, U., Martin, R., Stier, P., Wurzler, S., Feichter, J., Posselt, R., and Ferrachat, S.: Aerosol size-dependent belowcloud scavenging by rain and snow in the ECHAM5-HAM, Atmos. Chem. Phys., 9, 4653-4675, 2009,

http://www.atmos-chem-phys.net/9/4653/2009/.

Cui, Z., Carslaw, K. S., Yin, Y., and Davies, S.: A numerical study of aerosol effects on the dynamics and microphysics of a deep convective cloud in a continental environment, J. Geophys. Res., 111, D05 201, 2006.

Davis, C. and Auer, A.: The possibility of collision nucleation by an AgI aerosol in an orographic cap cloud, J. Rech. Atmos., 12, 107-115, 1972.

Davis, E. J. and Ravindran, P.: Single particle light scattering measurements using the electrodynamic balance, Aerosol Sci. Tech., 1, 337-350, 1982.

DeMott, P.: Quantitative descriptions of ice formation mechanisms of silver iodide-type aerosols, Atmos. Res., 38, 63-99, 1995.

DeMott, P., Finnegan, W., and Grant, L.: An application of chemical kinetic theory and methodology to characterize the ice nucleating properties of aerosols used for weather modification., J. Clim. Appl. Meteorol., 22, 1190-1203, 1983.
DeMott, P., Chen, Y., Kreidenweis, S., Rogers, D., and Sherman, D. E.: Ice formation by black carbon particles, Geophys. Res. Lett., 26, 2429-2432, 1999.

DeMott, P., Sassen, K., Poellot, M., Baumgardner, D., Rogers, D., Brooks, S., Prenni, A., and Kreidenweis, S.: African dust aerosols as atmospheric ice nuclei, Geophys. Res. Lett, 30, 1732, 2003.

DeMott, P., Prenni, A., Liu, X., Kreidenweis, S., Petters, M., Twohy, C., Richardson, M., Eidhammer, T., and Rogers, D.: Predicting global atmospheric ice nuclei distributions and their impacts on climate, P. Natl. Acad. Sci., 107, 11 217-11 222, 2010.

Deshler, T.: Measurements of the rate at which submicron aerosol particles are scavenged by water drops, J. Aerosol Sci., 16, 399406, 1985.

Deshler, T. and Vali, G.: Atmospheric concentrations of submicron contact-freezing nuclei, J. Atmos. Sci., 49, 773-784, 1992.

Diehl, K. and Mitra, S.: A laboratory study of the effects of a kerosene-burner exhaust on ice nucleation and the evaporation rate of ice crystals, Atmos. Environ., 32, 3145-3151, 1998.

Diehl, K., Quick, C., Matthias-Maser, S., Mitra, S., and Jaenicke, R.: The ice nucleating ability of pollen Part I: Laboratory studies in deposition and condensation freezing modes, Atmos. Res., 58, 75-87, 2001.

Diehl, K., Matthias-Maser, S., Jaenicke, R., and Mitra, S.: The ice nucleating ability of pollen: Part II. Laboratory studies in immersion and contact freezing modes, Atmos. Res., 61, 125-133, 2002.

Diehl, K., Simmel, M., and Wurzler, S.: Numerical sensitivity studies on the impact of aerosol properties and drop freezing modes on the glaciation, microphysics and dynamics of clouds, J. Geophys. Res, 111, D07 202, 2006.

Diehl, K., Mitra, S., Szak?ll, M., von Blohn, N., Borrmann, S., and Pruppacher, H.: The Mainz Vertical Wind Tunnel Facility ?- A Review of 25 Years of Laboratory Experiments on Cloud Physics and Chemistry, ed.J. D. Pereira, 2011.

Djikaev, Y. and Ruckenstein, E.: Thermodynamics of heterogeneous crystal nucleation in contact and immersion modes, J. Phys. Chem. A, 112, 11 677-11 687, 2008.

Djikaev, Y., Tabazadeh, A., Hamill, P., and Reiss, H.: Thermodynamic conditions for the surface-stimulated crystallization of atmospheric droplets, J. Phys. Chem. A, 106, 10 247-10 253, 2002.

Duft, D. and Leisner, T.: Laboratory evidence for volumedominated nucleation of ice in supercooled water microdroplets, Atmos. Chem. Phys., 4, 1997-2000, 2004a.

Duft, D. and Leisner, T.: The index of refraction of supercooled solutions determined by the analysis of optical rainbow scattering from levitated droplets, Int. J. Mass Spectrom., 233, 61-65, 2004b.

Durant, A. and Shaw, R.: Evaporation freezing by contact nucleation inside-out, Geophys. Res. Lett., 32, L20 814, 2005.

Dymarska, M., Murray, B., Sun, L., Eastwood, M., Knopf, D., and Bertram, A.: Deposition ice nucleation on soot at temperatures relevant for the lower troposphere, J. Geophys. Res., 111, D04 204, 2006.

Fletcher, A.: High-Temperature Contact Nucleation of Supercooled Water by Organic Chemicals., J. Appl. Meteorol., 11, 988-993, 1972.

Fletcher, N.: Active sites and ice crystal nucleation, J. Atmos. Sci, 26, 1266-1271, 1969. 
Fletcher, N.: On contact nucleation, J. Atmos. Sci, 27, 1098-1099, 1970.

Fornea, A., Brooks, S., Dooley, J., and Saha, A.: Heterogeneous freezing of ice on atmospheric aerosols containing ash, soot, and soil, J. Geophys. Res., 114, D13 201, 2009.

Friedman, B., Kulkarni, G., Beránek, J., Zelenyuk, A., Thornton, J., and Cziczo, D.: Ice nucleation and droplet formation by bare and coated soot particles, J. Geophys. Res., 116, D17 203, 2011.

Fukuta, N.: A study of a mechanism for contact ice nucleation, J. Atmos. Sci, 32, 1597-1603, 1975a.

Fukuta, N.: Comments on 'A possible mechanism for contact nucleation', J. Atmos. Sci., 32, 2371-2373, 1975 b.

Gokhale, N. and Goold Jr, J.: Droplet Freezing by Surface Nucleation., J. Appl. Meteorol., 7, 870-874, 1968.

Gokhale, N. and Lewinter, O.: Microcinematographic Studies of Contact Nucleation., J. Appl. Meteorol., 10, 469-473, 1971.

Gokhale, N. and Spengler, J.: Freezing of Freely Suspended, Supercooled Water Drops by Contact Nucleation., J. Appl.Meteorol., 11, 157-160, 1972.

Gorbunov, B., Baklanov, A., Kakutkina, N., Windsor, H., and Toumi, R.: Ice nucleation on soot particles, J. Aerosol Sci., 32, 199-215, 2001

Grant, L. and Steele, R.: The calibration of silver iodide generators, B. Am. Meteor. Soc, 47, 713-717, 1966.

Greenfield, S.: Rain scavenging of radioactive particulate matter from the atmosphere, J. Atmos. Sci., 14, 115-125, 1957.

Guenadiev, N.: Sur le mécanisme de congélation des gouttes d?eau sous l?influence d? un aerosol d?iodure d?argent, J. Rech. Atmos, 4, 81-91, 1970.

Gurganus, C., Kostinski, A., and Shaw, R.: Fast Imaging of Freezing Drops: No Preference for Nucleation at the Contact Line, J. Phys. Chem. Lett., 2, 1449-1454, 2011.

Gurganus, C., Kostinski, A., and Shaw, R.: High Speed Imaging of Freezing Drops: Still No Preference for the Contact Line, J. Phys. Chem. C, 117, 6195-6200, 2013.

Herbert, F. and Beheng, K.: Scavenging of airborne particles by collision with water drops?-Model studies on the combined effect of essential microdynamic mechanisms, Meteorol. Atmos. Phys., 35, 201-211, 1986.

Hobbs, P. V. and Atkinson, D. G.: The concentrations of ice particles in orographic clouds and cyclonic storms over the Cascade Mountains., J. Atmos. Sci., 33, 1362-1374, 1976.

Hobbs, P. V. and Rangno, A. L.: Ice particle concentrations in clouds, J. Atmos. Sci., 42, 2523-2549, 1985.

Hoffmann, N., Duft, D., Kiselev, A., and Leisner, T.: Contact freezing efficiency of mineral dust aerosols studied in an electrodynamic balance: Quantitative size and temperature dependence for illite particles., Faraday Discuss., p. DOI:10.1039/C3FD00033H, 2013a.

Hoffmann, N., Kiselev, A., Rzesanke, D., Duft, D., and Leisner, T.: Experimental quantification of contact freezing in an electrodynamic balance, Atmos. Meas. Tech. Discuss, 6, 3407-3437, $2013 b$.

Hoose, C. and Möhler, O.: Heterogeneous ice nucleation on atmospheric aerosols: a review of results from laboratory experiments, Atmos. Chem. Phys., 12, 9817-9854, 2012,

http://www.atmos-chem-phys.net/12/9817/2012/.

Hoose, C., Kristjánsson, J., Chen, J., and Hazra, A.: A ClassicalTheory-Based Parameterization of Heterogeneous Ice Nucle- ation by Mineral Dust, Soot, and Biological Particles in a Global Climate Model, J. Atmos. Sci., 67, 2483-2503, 2010.

Hussain, K. and Saunders, C.: Ice nucleus measurement with a continuous flow chamber, Q. J. Roy. Meteor. Soc., 110, 75-84, 1984.

Isaac, G. and Douglas, R.: Another "Time Lag" in the Activation of Atmospheric Ice Nuclei., J. Appl. Meteorol., 11, 490-493, 1972.

Kanji, Z. and Abbatt, J.: The University of Toronto Continuous Flow Diffusion Chamber (UT-CFDC): A Simple Design for Ice Nucleation Studies, Aerosol Sci. Tech., 43, 730-738, 2009.

Knopf, D. A. and Alpert, P. A.: A Water Activity Based Model of Heterogeneous Ice Nucleation Kinetics for Freezing of Water and Aqueous Solution Droplets, Faraday Discuss., p. doi:10.1039/C3FD00035D, 2013.

Koop, T., Ng, H. P., Molina, L. T., and Molina, M. J.: A new optical technique to study aerosol phase transitions: The nucleation of ice from H2SO4 aerosols, J. Phys. Chem. A, 102, 8924-8931, 1998.

Ladino, L.: Experimental study on collection efficiency and contact freezing of aerosols in a new collision chamber, ETH Zurich, $\mathrm{PhD}$. Thesis, 2011.

Ladino, L., Stetzer, O., Hattendorf, B., Günther, D., Croft, B., and Lohmann, U.: Experimental study of collection efficiencies between submicron aerosols and cloud droplets, J. Atmos. Sci., 68, 1853-1864, 2011a.

Ladino, L., Stetzer, O., Lüönd, F., Welti, A., and Lohmann, U.: Contact freezing experiments of kaolinite particles with cloud droplets, J. Geophys. Res, 116, D22 202, 2011 b.

Ladino, L. A., Zhou, S., Aljawhary, D., Yakobi-Hancock, J., and Abbatt, J. P. D.: $\alpha$-pinene SOA as Ice Nuclei: The Role of Increased Viscosity at Low Temperature, Geophys. Res. Lett., submitted, 2013.

Lai, K., Dayan, N., and Kerker, M.: Scavenging of aerosol particles by a falling water drop, J. Atmos. Sci., 35, 674-682, 1978.

Langer, G.: Evaluation of NCAR Ice Nucleus Counter. Part I: Basic Operation., J. Appl. Meteorol., 12, 1000-1011, 1973.

Langer, G., Rosinski, J., and Edwards, P.: A continuous ice nucleus counter and its applications to tracking in the troposphere, J. Appl. Meteorol., 6, 114-125, 1967.

Langer, G., Cooper, G., Nagamoto, C., and Rosinski, J.: Ice Nucleation Mechanisms of Submicron Monodispersed Silver Iodide, 1, 5-Dihydroxynaphthalene and Phloroglucinol Aerosol Particles., J. Appl. Meteorol., 17, 1039-1048, 1978.

$\mathrm{Lau}, \mathrm{K}$. and $\mathrm{Wu}, \mathrm{H} .:$ Warm rain processes over tropical oceans and climate implications, Geophys. Res. Lett, 30, 2290, 2003.

Leong, K., Beard, K., and Ochs III, H.: Laboratory measurements of particle capture by evaporating cloud drops, J. Atmos. Sci., 39, 1130-1140, 1982.

Levin, Z. and Yankofsky, S.: Contact versus immersion freezing of freely suspended droplets by bacterial ice nuclei, J. Clim. Appl. Meteorol., pp. 1964-1966, 1983.

Lohmann, U.: Possible aerosol effects on ice clouds via contact nucleation, J. Atmos. Sci., 59, 647-656, 2002.

Lohmann, U. and Diehl, K.: Sensitivity studies of the importance of dust ice nuclei for the indirect aerosol effect on stratiform mixedphase clouds, J. Atmos. Sci., 63, 968-982, 2006.

Lohmann, U. and Feichter, J.: Global indirect aerosol effects: a review, Atmos. Chem. Phys, 5, 715-737, 2005.

Lüönd, F., Stetzer, O., Welti, A., and Lohmann, U.: Experimental study on the ice nucleation ability of size-selected kaolinite par- 
ticles in the immersion mode, J. Geophys. Res., 115, D14 201, 2010.

Marcolli, C., Gedamke, S., Peter, T., and Zobrist, B.: Efficiency of immersion mode ice nucleation on surrogates of mineral dust, Atmos. Chem. Phys., 7, 5081-5091, 2007,

http://www.atmos-chem-phys.net/7/5081/2007/.

Meyers, M., Demott, P., and Cotton, W.: New primary icenucleation parameterizations in an explicit cloud model, J. Appl. Meteorol., 31, 708-721, 1992.

Möhler, O., Büttner, S., Linke, C., Schnaiter, M., Saathoff, H., Stetzer, O., Wagner, R., Krämer, M., Mangold, A., Ebert, V., et al.: Effect of sulfuric acid coating on heterogeneous ice nucleation by soot aerosol particles, J. Geophys. Res, 110, D11 210, 2005.

Morrison, H., Pinto, J., Curry, J., and McFarquhar, G.: Sensitivity of modeled arctic mixed-phase stratocumulus to cloud condensation and ice nuclei over regionally varying surface conditions, J. Geophys. Res, 113, D05 203, 2008.

Mossop, S.: Atmospheric ice nuclei, Zeitschrift für Angewandte Mathematik und Physik (ZAMP), 14, 456-486, 1963.

Murray, B., Wilson, T., Dobbie, S., Cui, Z., Al-Jumur, S., Möhler, O., Schnaiter, M., Wagner, R., Benz, S., Niemand, M., et al.: Heterogeneous nucleation of ice particles on glassy aerosols under cirrus conditions, Nature Geoscience, 3, 233-237, 2010.

Murray, B., Broadley, S., Wilson, T., Atkinson, J., and Wills, R.: Heterogeneous freezing of water droplets containing kaolinite particles, Atmos. Chem. Phys, 11, 4191-4207, 2011.

Murray, B., O'Sullivan, D., Atkinson, J., and Webb, M.: Ice nucleation by particles immersed in supercooled cloud droplets, Chem. Soc. Rev., 41, 6519-6554, 2012.

Nicolet, M., Stetzer, O., Lüönd, F., Möhler, O., and Lohmann: Single ice crystal measurements during nucleation experiments with the depolarization detector IODE, Atmos. Chem. Phys., 10, 313325, 2010,

http://www.atmos-chem-phys.net/10/313/2010/.

Niedermeier, D., Hartmann, S., Shaw, R., Covert, D., Mentel, T., Schneider, J., Poulain, L., Reitz, P., Spindler, C., Clauss, T., et al.: Heterogeneous freezing of droplets with immersed mineral dust particles-measurements and parameterization, Atmos. Chem. Phys., 10, 3601-3614, 2010,

http://www.atmos-chem-phys.net/10/3601/2010/.

Niemand, M., Möhler, O., Vogel, B., Vogel, H., Hoose, C., Connolly, P., Klein, H., Bingemer, H., DeMott, P., Skrotzki, J., et al.: A particle-surface-area-based parameterization of immersion freezing on desert dust particles, J. Atmos. Sci., 69, 30773092, 2012.

Park, S., Jung, C., Jung, K., Lee, B., and Lee, K.: Wet scrubbing of polydisperse aerosols by freely falling droplets, J. Aerosol Sci., 36, 1444-1458, 2005.

Phillips, V., DeMott, P., and Andronache, C.: An empirical parameterization of heterogeneous ice nucleation for multiple chemical species of aerosol, J. Atmos. Sci, 65, 2757-2783, 2008.

Phillips, V. T., Donner, L. J., and Garner, S. T.: Nucleation processes in deep convection simulated by a cloud-system-resolving model with double-moment bulk microphysics, J. Atmos. Sci., 64, 738761, 2007.

Pitter, R. and Pruppacher, H.: A wind tunnel investigation of freezing of small water drops falling at terminal velocity in air, Q. J. Roy. Meteor. Soc., 99, 540-550, 1973.
Pranesha, T. and Kamra, A.: Scavenging of aerosol particles by large water drops 1. Neutral case, J. Geophys. Res., 101, $23373-$ 23 380, 1996.

Pruppacher, H. and Klett, J.: Microphysics of Clouds and Precipitation, 954 pp, Reidel, Dordrecht, 1997.

Pruppacher, H. and Neiburger, M.: The UCLA cloud tunnel., Am. Meteor. Soc, pp. 289-392, 1968.

Rau, W.: Uber die Wirkungsweise der Gerfrierkerne im unterkuhlen Wasser, Zeit. Naturforsch., 5, 667-675, 1950.

Rigg, Y., Alpert, P., and Knopf, D.: Immersion freezing of water and aqueous ammonium sulfate droplets initiated by humic-like substances as a function of water activity, Atmos. Chem. Phys, 13, 6603-6622, 2013.

Roberts, P. and Hallett, J.: A laboratory study of the ice nucleating properties of some mineral particulates, Q. J. Roy. Meteor. Soc., 94, 25-34, 1968.

Rogers, D.: Development of a continuous flow thermal gradient diffusion chamber for ice nucleation studies, Atmos. Res., 22, 149181, 1988.

Rogers, D.: Measurements of natural ice nuclei with a continuous flow diffusion chamber, Atmos. Res., 29, 209-228, 1993.

Rosinski, J. and Nagamoto, C.: Contact nucleation of ice by natural aerosol particles, J. Aerosol Sci., 7, 1-4, 1976.

Sax, R. and Goldsmith, P.: Nucleation of water drops by Brownian contact with AgI and other aerosols, Q. J. Roy. Meteor. Soc., 98, 60-72, 1972.

Schaller, R. and Fukuta, N.: Ice nucleation by aerosol particles: Experimental studies using a wedge-shaped ice thermal diffusion chamber., J. Atmos. Sci., 36, 1788-1802, 1979.

Sear, R.: Nucleation at contact lines where fluid-fluid interfaces meet solid surfaces, J. Phys. Condens. Mat., 19, 466 106, 2007.

Seifert, P., Ansmann, A., Groß, S., Freudenthaler, V., Heinold, B., Hiebsch, A., Mattis, I., Schmidt, J., Schnell, F., Tesche, M., et al.: Ice formation in ash-influenced clouds after the eruption of the Eyjafjallajökull volcano in April 2010, J. Geophys. Res., 116, D00U04, 2011.

Shaw, R., Durant, A., and Mi, Y.: Heterogeneous surface crystallization observed in undercooled water, J. Phys. Chem. B, 109, 9865-9868, 2005.

Slinn, W. and Hales, J.: A reevaluation of the role of thermophoresis as a mechanism of in-and below-cloud scavenging, J. Atmos. Sci, 28, 1465-1471, 1971.

Slowik, J., Cziczo, D., and Abbatt, J.: Analysis of cloud condensation nuclei composition and growth kinetics using a pumped counterflow virtual impactor and aerosol mass spectrometer, Meas. Tech, 4, 1677-1688, 2011.

Soonsin, V., Zardini, A. A., Marcolli, C., Zuend, A., and Krieger, U.K.: The vapor pressures and activities of dicarboxylic acids reconsidered: the impact of the physical state of the aerosol, Atmos. Chem. Phys., 10, 11 753-11 767, 2010, http://www.atmos-chem-phys.net/10/11753/2010/.

Stetzer, O., Baschek, B., Lüönd, F., and Lohmann, U.: The Zurich Ice Nucleation Chamber (ZINC)-A new instrument to investigate atmospheric ice formation, Aerosol Sci. Tech., 42, 64-74, 2008.

Stöckel, P., Weidinger, I. M., Baumgärtel, H., and Leisner, T.: Rates of homogeneous ice nucleation in levitated $\mathrm{H} 2 \mathrm{O}$ and D2O droplets, J. Phys. Chem. A, 109, 2540-2546, 2005.

Stubenrauch, C., Cros, S., Guignard, A., and Lamquin, N.: A 6-year global cloud climatology from the Atmospheric In- 
fraRed Sounder AIRS and a statistical analysis in synergy with CALIPSO and CloudSat, Atmos. Chem. Phys., 10, 7197-7214, 2010 , http://www.atmos-chem-phys.net/10/7197/2010/.

Super, A., Boe, B., Heimbach Jr, J., McPartland, J., and Langer, G.: Comparison of silver iodide outputs from two different generators and solutions measured by acustic ice nucleus counters, Journal of Weather Modification, 42, 49, 2010.

Suzuki, S., Nakajima, A., Yoshida, N., Sakai, M., Hashimoto, A., Kameshima, Y., and Okada, K.: Freezing of water droplets on silicon surfaces coated with various silanes, Chem. Phys. Lett., 445, 37-41, 2007.

Svensson, E., Delval, C., Von Hessberg, P., Johnson, M., and Pettersson, J.: Freezing of water droplets colliding with kaolinite particles, Atmos. Chem. Phys., 9, 4295-4300, 2009, http://www.atmos-chem-phys.net/9/4295/2009/.

Szakáll, M., Mitra, S. K., Diehl, K., and Borrmann, S.: Shapes and oscillations of falling raindrops?A review, Atmos. Res., 97, 416425, 2010.

Tabazadeh, A., Djikaev, Y., and Reiss, H.: Surface crystallization of supercooled water in clouds, P. Natl. Acad. Sci., 99, $15873-$ $15878,2002$.

Tinsley, B., Rohrbaugh, R., and Hei, M.: Electroscavenging in clouds with broad droplet size distributions and weak electrification, Atmos. Res., 59, 115-135, 2001.

Tomlinson, E. and Fukuta, N.: A new horizontal gradient, continuous flow, ice thermal diffusion chamber, J. Atmos. Ocean. Tech., 2, 448-467, 1985.

Trenberth, K., Fasullo, J., and Kiehl, J.: Earth's global energy budget, B. Am. Meteorol. Soc, 90, 311-323, 2009.

Twohy, C. H., DeMott, P. J., Pratt, K. A., Subramanian, R., Kok, G. L., Murphy, S. M., Lersch, T., Heymsfield, A. J., Wang, Z., Prather, K. A., et al.: Relationships of biomass-burning aerosols to ice in orographic wave clouds, J. Atmos. Sci, 67, 2437-2450, 2010.

Vali, G.: Nucleation terminology, J. Aerosol Sci., 16, 575-576, 1985.

Vali, G.: Ice Nucleation-Theory: A Tutorial, in: NCAR/ASP 1999 Summer Colloquium, 1999.

Vali, G.: Repeatability and randomness in heterogeneous freezing nucleation, Atmos. Chem. Phys., 8, 5017-5031, 2008, http://www.atmos-chem-phys.net/8/5017/2008/.

Vohl, O., Mitra, S., Diehl, K., Huber, G., Wurzler, S., Kratz, K., and Pruppacher, H.: A wind tunnel study of turbulence effects on the scavenging of aerosol particles by water drops, J. Atmos. Sci., 58, 3064-3072, 2001.
Von Blohn, N., Mitra, S., Diehl, K., and Borrmann, S.: The ice nucleating ability of pollen Part III: New laboratory studies in immersion and contact freezing modes including more pollen types, Atmos. Res., 78, 182-189, 2005.

Wagner, R., Möhler, O., Saathoff, H., Schnaiter, M., Skrotzki, J., Leisner, T., Wilson, T., Malkin, T., and Murray, B.: Ice cloud processing of ultra-viscous/glassy aerosol particles leads to enhanced ice nucleation ability, Atmos. Chem. Phys, 12, 85898610, 2012.

Wang, B., Lambe, A., Massoli, P., Onasch, T., Davidovits, P., Worsnop, D., and Knopf, D.: The deposition ice nucleation and immersion freezing potential of amorphous secondary organic aerosol: Pathways for ice and mixed-phase cloud formation, J. Geophys. Res., 117, D16 209, 2012.

Wang, P., Grover, S., and Pruppacher, H.: On the effect of electric charges on the scavenging of aerosol particles by clouds and small raindrops, J. Atmos. Sci., 35, 1735-1743, 1978.

Wieringa, J. and Holleman, I.: If cannons cannot fight hail, what else?, Meteorologische Zeitschrift, 15, 659-669, 2006.

Wilson, T., Murray, B., Wagner, R., Möhler, O., Saathoff, H., Schnaiter, M., Skrotzki, J., Price, H., Malkin, T., Dobbie, S., et al.: Glassy aerosols with a range of compositions nucleate ice heterogeneously at cirrus temperatures, Atmos. Chem. Phys, 12, 8611-8632, 2012.

Wise, M., Baustian, K., Koop, T., Freedman, M., Jensen, E., and Tolbert, M.: Depositional ice nucleation onto crystalline hydrated $\mathrm{NaCl}$ particles: a new mechanism for ice formation in the troposphere, Atmos. Chem. Phys, 12, 1121-1134, 2012.

Young, K.: The role of contact nucleation in ice phase initiation in clouds, J. Atmos. Sci., 31, 768-776, 1974a.

Young, K.: A numerical simulation of wintertime, orographic precipitation: Part I. Description of model microphysics and numerical techniques., J. Atmos. Sci., 31, 1735-1748, 1974 b.

Zardini, A., Krieger, U., and Marcolli, C.: White light Mie resonance spectroscopy used to measure very low vapor pressures of substances in aqueous solution aerosol particles, Opt. Express, 14, 6951-6962, 2006. 